\title{
FORCE, MASS, AND ENERGY BUDGETS OF THE CRARY ICE RISE COMPLEX, ANTARCTICA
}

\author{
By D.R. MACAYEAL, \\ (Department of Geophysical Sciences, University of Chicago, Chicago, Illinois 60637, U.S.A.) \\ R.A. BINDSCHADLER, \\ (Laboratory for Oceans and Ice, NASA/Goddard Space Flight Center, Greenbelt, Maryland 20771, U.S.A.)
}

S. Shabtaie,

(Geophysical and Polar Research Center, Department of Geology and Geophysics,

University of Wisconsin-Madison, Madison, Wisconsin 53706, U.S.A.)

S. STEPHENSON,

(Laboratory for Oceans and Ice, NASA/Goddard Space Flight Center, Greenbelt, Maryland 20771, U.S.A.) and C.R. BENTLEY

(Geophysical and Polar Research Center, Department of Geology and Geophysics,

University of Wisconsin-Madison, Madison, Wisconsin 53706, U.S.A.)

\begin{abstract}
Resistive force exerted by the Crary Ice Rise on its ice-shelf/ice-stream environment and backpressure force transmitted across the grounding lines of Ice Streams A and B are calculated from airborne radio echo-sounding data and measurements of surface strain-rates. Resistance generated by the ice rise ranges in magnitude between 45 and $51 \%$ of the back-pressure force on the ice streams (depending on the flow law). The mechanical-energy budget of the ice rise is computed by considering work done against frictional forces at the perimeter of the ice rise and gravitational potential energy fluxes associated with changing mass distribution in the ice/ocean system. Energy dissipated by flow surrounding the ice rise is balanced by potential energy released within Ice Streams A and B, and accounts for between 15 and $49 \%$ of the work done by the ice streams against ice-shelf back pressure at their grounding lines. Mass balance of the ice rise, and the discharge of Ice Streams A and B, are calculated from surface-velocity and snow-accumulation measurements. The ice rise and its immediate environment gain mass by advection and snowfall at a rate equivalent to an area-averaged thickening rate of $0.44 \pm 0.06 \mathrm{~m} /$ year. This mass gain may be balanced by regional basal melting (which we do not measure), or could contribute to ice-rise expansion through regional thickening and ice-shelf grounding. Approximately $1 / 4$ to $1 / 2$ of the excess volume discharged by Ice Streams A and B above snow accumulation in their catchment areas is deposited in the vicinity of the ice rise (or melted from the bottom of the ice shelf). This suggests that the ice rise may have formed as a consequence of recent ice-stream acceleration, and that its continued growth may eventually reverse this trend of ice-stream discharge.
\end{abstract}

\section{INTRODUCTION}

Large-scale ice-shelf flow is resisted in part by smallscale obstructions occurring wherever the ice shelf grounds on the sea bed (Thomas, 1979[a]). These obstructions are termed ice rises if the surrounding ice-shelf flow is diverted around the perimeter of grounded ice, or ice rumples if the ice shelf flows over the grounded region. Field surveys and simple model treatments of the Ross Ice Shelf in West Antarctica suggest that ice rises play a major role in regulating ice discharge off the grounded continental ice sheet (Thomas and others, 1979; Thomas and MacAyeal, 1982). Crary Ice Rise shown in Figure 1, for example, is thought to reduce horizontal spreading rates along the grounding lines of Ice Streams A and B at a rate several orders of magnitude below that which would occur without the ice rise (Thomas and MacAyeal, 1982). Given their small size, and that climatic conditions could erode their perimeters under appropriate circumstances, ice rises and rumples are considered critical features in determining the climatic sensitivity of the West Antarctic ice shelves and the marine-based ice sheet which feeds them (Thomas, 1979[a], [b]).

To understand better the role of ice rises and ice rumples in the maintenance of large-scale ice-shelf flow, stress scales and other physical parameters governing ice-rise/ice-shelf coupling must be better understood. A physical basis for predicting ice-rise resistance in terms of such parameters as size, shape, and crevasse conditions would be useful, for example, in research concerning the time evolution of the West Antarctic ice sheet. An additional objective is to understand how ice rises typically originate, and to determine whether their formation or decay accompanies other time-dependent fluctuations of the surrounding ice shelf or ice streams. Such an understanding would aid the interpretation of present-day features in terms of past history of the West Antarctic ice sheet, and would help to predict possible consequences of present-day imbalance detected in the mass budgets of certain ice streams (see Shabtaie and Bentley, 1987).

As a step towards these goals, we present an analysis of the stress, mass, and energy-dissipation budgets of Crary Ice Rise located on the Ross Ice Shelf (Fig. 1) using field data collected during the 1983-85 austral summers and in previous field programs. We additionally calculate the net back pressure and ice-discharge rate along the grounding lines of Ice Streams A and B (Fig. 1) to assess the effect of the ice rise on the surrounding flow. Comparison of the ice-rise budgets with the analysis of grounding-line data confirms the influence of the ice rise on ice-sheet stability, and suggests that Crary Ice Rise may have formed recently in response to an acceleration of Ice Stream B. We speculate that feed-back between ice-stream acceleration and ice-rise formation may control the future evolution of Ice Stream B and promote long-term grounding-line stability in the face of strong natural fluctuations. 


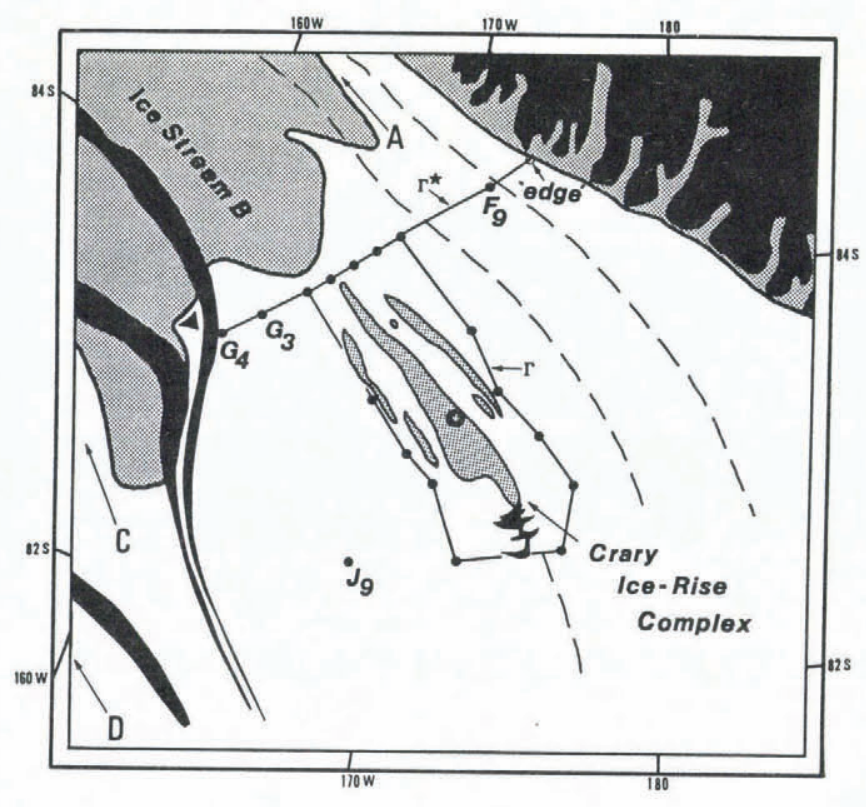

Fig. 1. The Crary Ice Rise complex at the outlets of Ice Streams $A$ and $B$ (polar stereographic projection). Light shading represents grounded ice. Heavy shading in upper right represents the Transantarctic Mountains range and the East Antarctic ice sheet. Clear regions represent floating Ross Ice Shelf. Darkened stripes on left and broken lines represent tracer trajectories mapped by radio echo-sounding (Shabtaie and Bentley, 1987). The up-stream origins of the darkened stripes are the heavily crevassed margins which delineate the ice streams (labeled A through D). The dark irregular patch just down-stream of the largest ice rise represents its rifted wake. Field-measurement stations (some labeled, see also Figure 2) are represented by (๑), and most are connected together by radio echo-sounding flight lines to form contours $\Gamma$ and $\Gamma^{*}$. We use our field data (and that reported by Thomas and others (1984)) to compute the force, mass, and mechanical-energy budgets of the region enclosed by i (the Crary Ice Rise complex). To investigate the influence of the ice-rise complex on the surrounding ice streams, we compare these budgets with those calculated for the ice-stream gateway contour [*. Station $E_{4}$ (shown by star) is designated as the projection pole for projecting our study region stereographically on to the $x, y$-plane (all figures, however, are standard south-pole referenced stereographic projections). Coordinate axes $x$ and $y$ are defined in Table IV.

\section{FIELD PROGRAM}

To determine the force, mass, and mechanical-energy dissipation budgets of Crary Ice Rise, it was necessary to measure its thickness, velocity, and strain-rate around the perimeter of the ice rise. We performed these measurements along an imaginary contour designated $\Gamma$ in Figures 1 and 2. This contour encloses the ice rise as well as parts of the surrounding ice shelf, and lies entirely on floating ice shelf (except possibly for several kilometers constructed over ice-shelf rifts or ice rumples not identified prior to the field operation; Figure 2). 「 was used instead of the natural perimeter of the ice rise for the following reasons: (1) the natural perimeter is not clearly defined or accessible, (2) the effects of severe crevassing typically found along the perimeter on ice flow are not known, and (3) surface measurements of strain-rate and velocity taken on floating ice sufficiently far from the ice-rise boundary are naturally representative of flow at depth (see Sanderson and Doake, 1979; and Morland, 1987, for a discussion of lead-order ice-shelf flow characteristics including the absence of significant vertical shear).

The contour $r$ was constructed by establishing a boxlike pattern of surface stations surrounding the ice-rise complex, and by connecting these stations with airborne radar-sounding flight lines as shown in Figures 1 and 2 . Velocity and strain-rate measured at these surface stations during our 1983-85 field operations are summarized in Table I. Data from three surface stations along $\Gamma\left(\mathrm{J}_{10}, \mathrm{~J}_{11}\right.$, and $I_{11}$ in Figure 2) were acquired by Thomas and others (1984) during the Ross Ice Shelf Geophysical and Glaciological Survey (RIGGS) (see also Bentley, 1984). Radio echo-sounding data are reported by Shabtaie and Bentley (1987), and are presented in Figure 3. Additional data collected during the $1983-85$ operations or during RIGGS are presented in some figures to improve the display of regional flow conditions (see paper in preparation by R.A. Bindschadler and others for a detailed listing of these regional data).

As a result of the radio echo-sounding surveys conducted during our field operations (see Shabtaie and Bentley (1987) for details concerning flight lines not shown in Figures 1, 2, or 3), the ice-rise perimeter was found to encompass a greater area than that shown on previous maps (e.g. Drewry, 1983). Shabtaie and Bentley (1987) described the ice rise as consisting of a main oblong island of grounded ice, here referred to as Crary Ice Rise A, surrounded by possible "outrigger" ice rises, rumples, or crevasse-free ice-shelf "rafts" here referred to as Crary Ice Rises B through E. Crary Ice Rise F was identified as an ice rumple by a tidal tilt-meter survey performed in concert

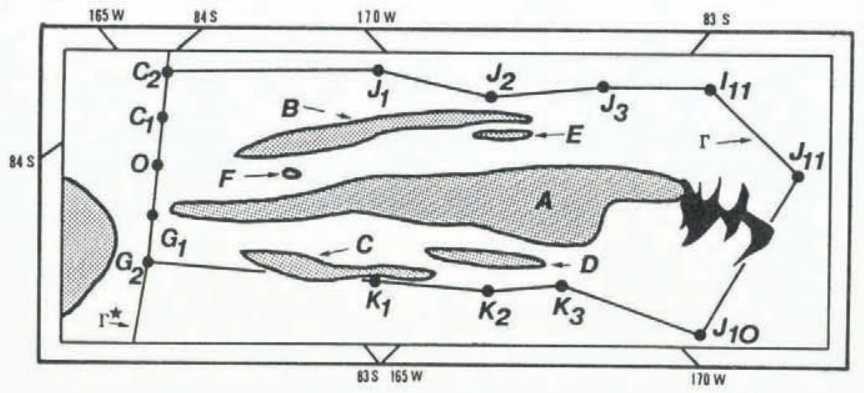

Fig. 2. The Crary Ice Rise complex in detail. The configuration of the complex was determined by Shabtaie and Bentley (1987) using radar-mapping techniques. Ice velocities over most of component $A$ are near zero indicating that this largest part of the complex is a true ice rise. Components $B-E$ are clutter-free regions in the radio echo-sounding records. Component $\boldsymbol{F}$ was detected by tilt-meter analysis of tidal flexure (personal communication from $S$. Stephenson) and is known to be an ice rumple. Selected field stations along contours $\Gamma$ and $\Gamma^{*}$ are labeled.

with ground-based radio echo-sounding (Bindschadler and others, 1987).

Surface-elevation and velocity measurements confirm that Crary Ice Rise A is indeed grounded, and that large parts of it are motionless with respect to the general flow of the surrounding ice shelf (Bindschadler and others, in press). Ice Rises $\mathbf{B}$ through $\mathrm{E}$, however, are detected by their clutter-free radio-echo signatures denoting the marked absence of surface crevasses within heavily crevassed perimeters common to other, confirmed ice rises. Inasmuch as these outlying features cannot unambiguously be identified as ice rises, ice rumples, or simply regions of crevasse-free ice shelf, we refer to the entire collection of features as the Crary Ice Rise "complex".

Two other contours, $\Gamma^{*}$ and $\Gamma^{c}$, were constructed to examine the force, mass flux, and energy dissipation along the grounding line of Ice Streams $\mathbf{A}$ and $\mathbf{B}$, and within control region of the Ross Ice Shelf (to test our methods in an ice-rise-free environment), respectively. The ice-stream grounding-line contour (Fig. 1) was constructed from eight line segments joining surface stations extending between $G_{4}$ on the northern edge of Ice Stream $B$ to the edge of the ice shelf along the Transantarctic Mountains. As with $\Gamma$, $\Gamma^{*}$ is constructed outside the natural perimeter of grounded ice to avoid uncertainties in mapping the grounding line and to 
TABLE I

Station
source

Azimuth of
velocity

$\mathrm{m} /$ year

SURFACE STATIONS DEFINING $\Gamma^{(2)}$

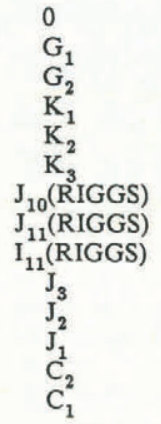

324
$(321)$
$(318)$
225
224
239
388
$[468]$
$[447]$
377
333
387
458
$(391)$

307.0
$(314.8)$
$(322.5)$
326.0
323.0
313.0
319.0
$[343.6]$
$[341.5]$
328.0
314.5
310.0
296.2
$(301.6)$

STATIONS DEFINING $\Gamma^{*(2)}$

$\begin{array}{ccr}\mathrm{G}_{4}{ }^{(3)} & 271 & 342.0 \\ \mathrm{G}_{3}(3) & 312 & 338.0 \\ \mathrm{Fg}_{\mathrm{g}}(\mathrm{RIGGS})^{(3)} & 493 & 297.0 \\ \text { Eăge (estimated) })^{(3)} & (493) & (297.0\end{array}$

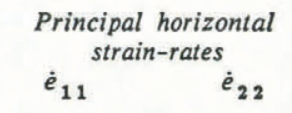

$\times 10^{-11} \mathrm{~s}^{-1} \times 10^{-11} \mathrm{~s}^{-1}$

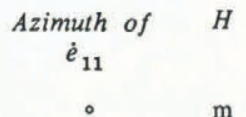

$\mathrm{m}$

$\begin{array}{rr}14.54 & -13.28 \\ 17.59 & -18.89 \\ 11.98 & -9.70 \\ 5.31 & -3.90 \\ 11.62 & -6.30 \\ 13.54 & -2.74 \\ 6.37 & -0.76 \\ 3.93 & -0.48 \\ 5.42 & -0.25 \\ 1.67 & 0.45 \\ 2.79 & -2.85 \\ 2.81 & -2.45 \\ 4.79 & -2.79 \\ 10.11 & -8.40\end{array}$

$53.0 \quad 696$

$45.1 \quad 673$

$41.7 \quad 648$

$334.1 \quad 519$

$354.8 \quad 454$

$357.8 \quad 399$

$170.0 \quad 329$

$147.0 \quad 385$

$57.0 \quad 502$

$318.3 \quad 583$

$69.2 \quad 618$

$49.4 \quad 734$

$54.0 \quad 710$
$96.1 \quad 581$
Position ( ${ }^{\prime}$ ")

lat. S. long. W.

\section{STATIONS DEFINING $\mathrm{r}^{\mathrm{C}(2)}$}

$\begin{array}{lc}\mathrm{P}_{14} \text { (RIGGS) } & (849) \\ \mathrm{Q}_{14}(\mathrm{RIGGS}) & 921 \\ \mathrm{R}_{14} \text { (RIGGS) } & (954) \\ \mathrm{R}_{15} \text { (RIGGS) } & 876 \\ \mathrm{Q}_{15} \text { (RIGGS) } & 842 \\ \mathrm{P}_{15} \text { (RIGGS) } & 798\end{array}$

$\begin{array}{crr}(11.7) & 4.44 & -2.73 \\ 10.5 & 2.31 & 0.19 \\ (9.0) & 3.49 & 1.55 \\ 9.5 & 1.93 & 1.62 \\ 13.1 & 2.69 & 0.16 \\ 17.2 & 4.44 & -2.73\end{array}$

102.7
51.1
172.0

(1) Values in $(\cdot)$ represent linear interpolations between stations that are aligned roughly along a straight segment of $\Gamma$.

Values in [ $\cdot]$ represent interpolations performed according to the method outlined in Thomas and others (1984).

(2) Sources: Bentley and others (1979); Thomas and others (1984); Bindschadler and others (in press); paper in preparation by R.A. Bindschadler and others.

(3) Station data for $G_{2}, G_{1}, 0, C_{1}$, and $C_{2}$ are in list of stations defining $\Gamma$.
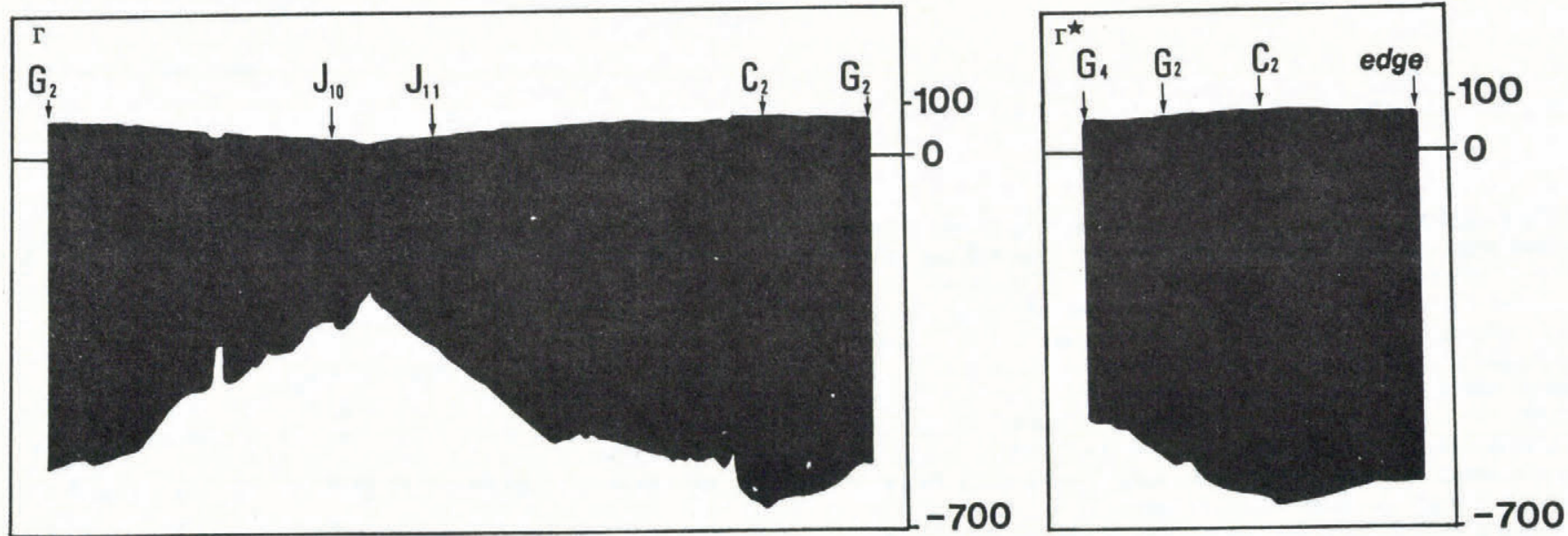

Fig. 3. Ice-thickness cross-sections (thickness scale on edge in meters) along contours $\Gamma$ and $\Gamma^{*}$ (Shabtaie and Bentley, 1987). 
exploit the advantage of performing surface measurements on floating ice. Six of the eight segments forming $\Gamma^{*}$ correspond to radio-echo flight lines. Thickness profiles along two segments $\left(C_{2}\right.$ to $F_{9}$ and $F_{9}$ to the edge) were extrapolated from RIGGS data (Bentley and others, 1979). Surface strain-rates were not measured at the station defining the edge of the ice shelf (Fig. 1), so the strainrates observed at $F_{9}$ were used along the entire segment connecting $\mathrm{F}_{9}$ to the edge in the analysis of force and energy dissipation. The error induced by this extrapolation is treated in the estimates of uncertainty which accompany our analysis.

The contour $\Gamma^{c}$ encloses an ice-rise-free part of the Ross Ice Shelf for use in a control experiment designed to test our data analysis and interpretation of ice-rise effects. This contour was constructed by connecting six RIGGS stations $\left(P_{14}, Q_{14}, R_{14}, R_{15}, Q_{15}\right.$, and $P_{15}$ shown by the map of field stations in Thomas and others (1984) and in Table I) in a closed circuit of line segments. Ice thickness along these segments was interpolated from surface radar measurements at the RIGGS stations. Strain-rates and velocities observed, or extrapolated from surrounding stations, at the six RIGGS stations used to construct $\Gamma^{c}$ are summarized in Table I.

\section{FORM DRAG AND DYNAMIC DRAG: THEORY}

We determine the reaction force exerted by the Crary Ice Rise complex on the surrounding ice shelf and the ice streams located up-stream by computing the net surface traction acting on $\Gamma$. This surface traction is partitioned into a glaciostatic contribution and a contribution arising from viscous friction associated with ice deformation, termed form drag and dynamic drag, respectively (MacAyeal, 1987; see also Whillans, 1987). This partition separates the resistive forces which depend on the constitutive properties of ice (dynamic drag) from those that do not (form drag).

The net surface traction vector $\boldsymbol{F}$ acting on the imaginary material surface surrounding the Crary complex is given by (see Jaeger, 1969, p. 5)

$$
\boldsymbol{F}=-\oint_{\Gamma}\left\{\int_{z_{\mathrm{b}}}^{z_{\mathrm{S}}} \mathbf{T} \cdot \boldsymbol{n d} z\right\} \mathrm{d} \lambda
$$

where $\quad \mathbf{T} \equiv$ the stress tensor, $\boldsymbol{n} \equiv$ the outward-pointing vector of unit magnitude on the boundary contour $\Gamma$ (this vector lies in the horizontal plane and points perpendicularly away from the Crary complex at each point on $\Gamma$ ), $z$ is the vertical coordinate (zero at sea-level, positive upwards), $z_{\mathrm{s}}$ and $z_{\mathrm{b}}$ are the $z$-coordinates of the surface and base of the ice shelf, respectively, and $d \lambda$ is the horizontal length element of $r$. We adopt the convention that $\boldsymbol{F}$ denotes the force acting on the surroundings of the Crary complex due to the physical features enclosed within $\Gamma$. This convention accounts for the minus sign appearing in Equation (1).

The stress tensor $\mathbf{T}$ satisfies the stress-equilibrium equations (Paterson, 1981, p. 84), which are considerably simplified for an ice shelf of small aspect ratio (ratio of thickness to horizontal extent) (Weertman, 1957; Morland, 1987): the vertical shear stresses, $T_{x z}$ and $T_{y z}$, are negligible and the surface traction T. $\boldsymbol{n}$ across any differential area element of $\Gamma$ lies in the horizontal plane. In this circumstance, the pressure $P=-1 / 3\left(T_{x x}+T_{y y}+T_{z z}\right)$,

$$
P(z)=\int_{z}^{z} \rho(\zeta) g \mathrm{~d} \zeta+T_{z z}^{\prime}
$$

where $\rho(z) \equiv$ local ice/firn density, $g=9.81 \mathrm{~m} / \mathrm{s}^{2}, \quad \zeta$ is a dummy variable of integration, $T_{z z}^{\prime}$ is the direct vertical component of the deviatoric stress $\mathbf{T}^{j}$ given by

$$
\mathbf{T}^{\prime}=\mathbf{T}+P I \text {. }
$$

$I$ is the identity tensor and $x$ and $y$ are horizontal coordinates.
With $\mathbf{T}$ given by Equation (3), and using Equation (2), Equation (1) becomes

$$
\boldsymbol{F}=-\oint_{\Gamma}\left\{\int_{z_{\mathrm{b}}}^{z_{\mathrm{S}}} \mathrm{T}^{\prime} \cdot n \mathrm{~d} z-\int_{z_{\mathrm{b}}}^{z_{\mathrm{S}}} T_{z z}^{\prime} n \mathrm{~d} z-\int_{z_{\mathrm{b}}}^{z_{\mathrm{s}}} \int_{z}^{z_{\mathrm{S}}} \rho(\zeta) g n \mathrm{~d} \zeta \mathrm{d} z\right\} \mathrm{d} \lambda .
$$

The right-hand side of Equation (4) is partitioned into the sum of the form drag and the dynamic drag $\left(F^{f}+F^{d}\right)$ by writing

$$
F^{\mathrm{f}}=\oint_{\Gamma} \int_{z_{\mathrm{b}}}^{z_{\mathrm{s}}}\left\{\int_{z}^{z_{\mathrm{s}}} \rho(\zeta) g \mathrm{~d} \zeta\right\} n \mathrm{~d} z \mathrm{~d} \lambda
$$

and

$$
F^{\mathrm{d}}=-\oint_{\Gamma} \int_{z_{\mathrm{b}}}^{z_{\mathrm{S}}}\left\{\mathrm{T}^{\prime} \cdot \boldsymbol{n}+\left(T_{x x}^{\prime}+T_{y y}^{\prime}\right) n\right\} \mathrm{d} z \mathrm{~d} \lambda
$$

where the incompressibility condition is used to substitute $\left(T_{x x^{\prime}}+T_{y y^{\prime}}\right)$ for $-T_{z z^{\prime}}$.

In our calculation of the form drag, we assume that the density-depth profile of the firn layer is spatially uniform and use the observed profile from drill site $\mathrm{J}_{9}$ (located near the ice-rise complex, Figure 1) as representative of the entire study region (Kirchner and others, 1979). The exponential profile which best fits the $\mathrm{J}_{9}$ data is given by

$$
\rho(z)=\rho_{\mathrm{i}}-\alpha \exp \left(\beta\left(z_{\mathrm{S}}-z\right)\right)
$$

where $\quad \alpha=608.0 \mathrm{~kg} / \mathrm{m}^{3}, \quad \beta=-0.043 \mathrm{~m}^{-1}$, and $\rho_{\mathrm{i}}=$ $917 \mathrm{~kg} / \mathrm{m}^{3}$. The integrals over $\zeta$ and $z$ in Equation (5) may thus be evaluated exactly giving

$$
F^{\mathrm{f}}=\oint_{\Gamma}\left\{\frac{1}{2} \rho_{\mathrm{i}} g H^{2}+\frac{\alpha}{\beta^{2}} g H+\frac{\alpha}{\beta^{2}}\left(1-\mathrm{e}^{\beta H}\right) g\right\} n \mathrm{~d} \lambda
$$

where $H=\left(z_{\mathrm{S}}-z_{\mathrm{b}}\right)$.

The second and third terms of the integrand on the right-hand side of Equation (8) represent a correction for the excess thickness of the ice shelf over a solid-ice shelf of the same mass. This correction is $15.4 \mathrm{~m}$, which is smaller than the $17.4 \mathrm{~m}$ average over the entire ice shelf (Shabtaie and Bentley, 1982). The low snow accumulation rates in our study area may account for this difference (Thomas and others, 1984).

\section{FLOW LAW}

The distinction between form and dynamic drags is advantageous from the standpoint that, for measurement from field data, only dynamic drag requires an assumed flow law. Lliboutry and Duval (1985) outlined the physical factors that affect ice flow, and emphasized that it is currently not possible to adopt a simple relationship defining ice response to stress that will account for all factors and apply to all flow regimes. Since few of the thermal and chemical characteristics affecting ice flow in our field area are known in detail, we adopt relatively simple flow laws that account for temperature and firn density only. Additionally, we present several calculations of $F^{\mathrm{d}}$ using alternative flow laws to demonstrate possible uncertainties inherent in our result.

Flow laws determined from laboratory and field experiments have been reviewed by Paterson (1981; see also 1985), Hooke (1981), Weertman (1983), and Doake and Wolff (1985[a]; see also 1985[b]). Following the trend of these reviews, we write the flow law in the following format:

$$
\dot{e}_{i j}=\left(\frac{T^{n-1}}{B^{n}}\right) T_{i j}{ }^{\prime}
$$

where $\dot{\mathrm{e}}$ is the strain-rate tensor, $\tau=\left\{\frac{1}{2}\left(T^{\prime}{ }_{i j} j^{\prime}{ }_{i j}\right)\right\}^{1 / 2}$ (summation convention is used), and $n$ is the flow-law exponent. The ice-stiffness parameter $B(\rho, \theta, n)$ accounts for the effect of temperature and density, and is given by 


$$
B(n, \theta, \rho)=B_{0} \exp \left\{\frac{Q}{n R \theta}\right\} \frac{\rho(z)-\rho\left(z_{\mathrm{S}}\right)}{\rho_{\mathrm{i}}-\rho\left(z_{\mathrm{S}}\right)}
$$

where $\theta$ is the temperature $\left({ }^{\circ} \mathrm{K}\right) . Q$ is the activation energy, $R=8.3143 \mathrm{~J} \mathrm{~mol}^{-1} \mathrm{deg}^{-1}$ is the gas constant, $B_{0}$ is a rate-determining parameter accounting for all the physical effects not explicitly treated, $\rho\left(z_{\mathrm{S}}\right)$ is the firn density at $z$ $=z_{\mathrm{S}}$, and $\rho_{\mathrm{i}}$ is the density of ice at depth $\left(917 \mathrm{~kg} / \mathrm{m}^{3}\right.$ ) (see Thomas and MacAyeal (1982) for discussion of density treatment). For convenience in treating our strain-rate data, we invert Equation (9) to express deviatoric stress in terms of strain-rate $\left(T^{\prime}{ }_{i j}=2 v \dot{e}_{i j}\right)$ using the effective viscosity

$$
v=\frac{B(n, \theta, \rho)}{2 \dot{\mathbf{e}}^{1-1 / n}}
$$

where $\dot{\mathbf{e}}=\left\{\frac{1}{2}\left(\dot{e}_{i j} \dot{e}_{i j}\right)\right\}^{1 / 2}$.

To illustrate the effects of flow-law uncertainty, we adopt three alternative sets of values for $B_{0}, Q$, and $n$ shown in Table II. The first two alternatives represent nonNewtonian flow laws (with $n=3$ ) commonly used in other to be approximately $0.2 \times 10^{8} \mathrm{~Pa} \mathrm{~s}^{1 / 3}$ for flow laws \#1 and \#2 (approximately $13 \%$ of the value of $\bar{B}^{z}$ ), and $1.5 \times$ $10^{14} \mathrm{Pas}$ (approximately $23 \%$ of the value of $\bar{B} z$ ) for flow law \#3 (see Thomas and_MacAyeal, 1982, fig. 7). We adopt a uniform value of $\bar{B}^{z}$ calculated from the observed temperature-depth profile at $\mathrm{J}_{9}$ (Clough and Hansen, 1979), and regard the effect of regional temperature variation as uncertainty.

The values of $\bar{B}^{z}$ calculated from $\mathrm{J}_{9}$ data using the three alternative flow laws and an evaluation of their uncertainty are presented in Table II. The two values of $\bar{B} z$ corresponding to flow laws $\# 1$ and $\# 2$ can be directly compared because $n$ is the same in each flow law. $\bar{B}^{z}$ calculated following Paterson's (1981) assessment of natural ice flow (flow law \#2) is smaller (yielding softer ice) than $\vec{B}^{z}$ calculated using the laboratory-derived flow law (flow law \#1), but is within the estimated uncertainty interval surrounding the laboratory-derived value.

\section{FORM DRAG AND DYNAMIC DRAG: MEASUREMENT}

To determine $\boldsymbol{F}^{\mathrm{f}}$ and $\boldsymbol{F}^{\mathrm{d}}$ from field data, we performed the integrations expressed in Equations (8) and

\begin{tabular}{|c|c|c|c|c|c|c|}
\hline Flow law & Source & Reference & & Flow-law parameters & $n$ & $\bar{B}^{z^{*}}$ \\
\hline$\# 1$ & Laboratory creep tests & $\begin{array}{l}\text { Barnes and others, } 1971 \\
\text { (see also Thomas and } \\
\text { MacA yeal, 1982) }\end{array}$ & $B_{0}=\{$ & $\left\{\begin{array}{l}1.3 \mathrm{~Pa} \mathrm{~s}^{1 / 3} \text { if } \theta \geqslant 260^{\circ} \mathrm{K} \\
625 \mathrm{~Pa} \mathrm{~s}^{1 / 3} \text { if } \theta<260^{\circ} \mathrm{K}\end{array}\right\} Q=\left\{\begin{array}{c}120 \mathrm{~kJ} \mathrm{~mol}^{-1} \text { if } \theta \geqslant 260^{\circ} \mathrm{K} \\
80 \mathrm{~kJ} \mathrm{~mol}^{-1} \text { if } \theta<260^{\circ} \mathrm{K}\end{array}\right\}$ & 3 & $(1.6 \pm 0.2) \times 10^{8} \mathrm{~Pa} \mathrm{~s}^{1 / 3}$ \\
\hline$\# 2$ & $\begin{array}{l}\text { Bore-hole tilt and ice- } \\
\text { shelf spreading }\end{array}$ & $\begin{array}{l}\text { Paterson, } 1981 \text { (see } \\
\text { table 3.3) }\end{array}$ & $B(n, \theta)=$ & $\begin{array}{l}=A(\theta)^{-1 / 3} \text { where } A \text { is interpolated linearly from table } 3.3 \text { of } \\
\text { Paterson }\left(1981 \text { (the activation energy } Q \text { is } 139 \mathrm{~kJ} \mathrm{~mol}^{-1}\right. \\
\text { if } \theta \geqslant 263.15^{\circ} \mathrm{K} \text {; and is } 60 \mathrm{~kJ} \mathrm{~mol}^{-1} \text { if } \theta<263.15^{\circ} \mathrm{K} \text { ) }\end{array}$ & 3 & $(1.4 \pm 0.2) \times 10^{8} \mathrm{~Pa} \mathrm{~s}^{1 / 3}$ \\
\hline$\approx 3$ & $\begin{array}{l}\text { Bore-hole tilt and ice- } \\
\text { shelf spreading }\end{array}$ & $\begin{array}{l}\text { Doake and Wolff, } \\
1985[\mathrm{a}], \text { [b] (see } \\
\text { also Paterson, 1985) }\end{array}$ & $B(n, \theta)^{\dagger}$ & $Q=60 \mathrm{~kJ} \mathrm{~mol}^{-1}$ & 1 & $(6.4 \pm 1.5) \times 10^{14} \mathrm{Pas}$ \\
\hline
\end{tabular}

TABLE II. ALTERNATIVE FLOW LAWS USED TO COMPUTE THE DYNAMIC DRAG AND ENERGY BUdGet FROM STRAIN-RATE DATA

Comments: *Calculated from the observed $\mathrm{J}_{9}$ temperature-depth and density-depth profiles.

${ }^{B}(n, \theta)$ for $n=1$ corresponds to $A_{1}=2.6 \times 10^{-15} \mathrm{~Pa}^{-1} \mathrm{~s}^{-1}$ at $-13^{\circ} \mathrm{C}$ in Doake and Wolff's

(1985[a]) re-analysis of Holdsworth's (1982) Erebus Glacier tongue data.

applications; the third represents a controversial Newtonian flow law (with $n=1$ ) recently proposed by Doake and Wolff (1985[a], [b]). Flow law \#1 represents parameter values used in other studies of Ross Ice Shelf field data (Thomas and MacAyeal, 1982; see also MacAyeal and others, 1986), and is based on laboratory measurements of ice creep (Barnes and others, 1971). Flow law $\# 2$ is based on Paterson's (1981, p. 39, table 3.3) compilation of natural ice-deformation data (bore-hole tilting and ice-shelf spreading; but modified to account for firn density as shown in Equation (10)). Flow law \#3 is adopted from Doake and Wolff's (1985[a], [b]) analysis of Holdsworth's (1982) Erebus Glacier tongue data which suggests a Newtonian $(n=1)$ rather than non-Newtonian $(n>1)$ rheology.

Expressing the dynamic drag in terms of the measured depth-independent strain-rate tensor and flow-law parameters gives:

$$
F^{\mathrm{d}}=-\oint_{\Gamma} 2 \bar{v}^{z} H\left\{\dot{e} \cdot n+\left(\dot{e}_{x x}+\dot{e}_{y y}\right) n\right\} \mathrm{d} \lambda
$$

where $H=\left(z_{\mathrm{S}}-z_{\mathrm{b}}\right)$ is the observed ice thickness,

$$
\bar{v}^{z}=\frac{\bar{B}^{z}}{2 \dot{e}^{1-1 / n}}
$$

and $\bar{B}^{z}$ is the depth-averaged value of $B(n, \theta, \rho) . \quad \bar{B}^{z}$ is determined by the local temperature-depth profile, and is thus influenced by snow accumulation, basal melting, and boundary temperatures at $z_{\mathrm{s}}$ and $z_{\mathrm{b}}$. Variation of $\bar{B}^{z}$ throughout the study area due to regional changes in the temperature-depth profile and uncertainty in the basal melting rate (assumed to be $0 \pm 0.1 \mathrm{~m} /$ year) was estimated
(12), respectively, using the analysis procedures summarized in the Appendix (Table A-I). In brief, we divided $\Gamma$ into 14 line segments on a polar stereographic projection (with station $\mathrm{E}_{4}$ at lat. $83^{\circ} 09^{\prime} 20^{\prime \prime} \mathrm{S}$., long. $171^{\circ} 36^{\prime} 38^{\prime \prime} \mathrm{W}$. designated as the projection pole to reduce map-distortion error, and denoted by the star in Figure 1) using 14 surface stations as segment end-points. Each of the 14 line segments was further divided into as many sub-segments as necessary to represent the ice-thickness profiles acquired from the radio echo-sounding records. Strain-rate components at points along the line segments were interpolated from the observed values at the end-points. The integrations required by Equations (8) and (12) were then performed using the trapezoidal method (Table A-I).

Confidence limits on the derived results were calculated using the technique summarized by Boas (1983, p. 734). Uncertainties due to measurement, navigation, and interpolation errors are summarized in Table III. Accuracy of ice thickness is estimated to be $8 \mathrm{~m}$ for flight lines conducted during our operations, and $15 \mathrm{~m}$ for the one RIGGS flight line used to connect stations $\mathrm{J}_{10}$ and $\mathrm{J}_{11}$ (Table III and Fig. 2). Three segments of $\Gamma\left(K_{3}\right.$ to $J_{10}, J_{11}$ to $I_{11}$, and $I_{11}$ to $J_{3}$ in Figure 2) that comprise the down-stream end of $r$ have thicknesses measured at their end-points only. For these segments, we interpolated the thickness profiles using the ice-thickness contour map derived from RIGGS (Bentley and others, 1979). Accuracy of these interpolated profiles is approximately $50 \mathrm{~m}(10 \%$ of the $520 \mathrm{~m}$ average ice thickness along $\Gamma$ ). Most of $\Gamma$ is located sufficiently far from the icerise boundaries to expect relatively smooth spatial variation in the flow field. Interpolation errors of the strain-rates are thus expected to be approximately $10 \%$ of the value of $\dot{e}=$ $\left(0.5 \dot{e}_{i j} \dot{e}_{i j}\right)^{1 / 2}$ averaged between the segment end-points (Table III).

The computed force budget is presented in Table IV 
TABLE III. MEASUREMENT AND INTERPOLATION UNCERTAINTY*

Variable

\begin{tabular}{|c|c|c|}
\hline$H$ & $\sigma_{H}$ & $\begin{array}{l}8 \mathrm{~m} \text { on our flight lines } \\
15 \mathrm{~m} \text { on RIGGS flight lines } \\
50 \mathrm{~m} \text { on extrapolated segments } \\
25 \mathrm{~m} \text { on control contour } \Gamma^{\mathrm{C}}\end{array}$ \\
\hline$\dot{e}$ & $\sigma_{\mathrm{e}}$ & $\begin{array}{l}10 \% \text { of average value of } \\
\dot{e}=\left\{\frac{1}{2} \dot{e}_{i j} \dot{e}_{i j}\right\}^{1 / 2} \text { along segment }\end{array}$ \\
\hline & $\sigma_{\mathrm{B}}$ & $\begin{array}{l}0.2 \times 10^{8} \mathrm{~Pa} \mathrm{~s}^{1 / 3} \text { for flow laws \#1 } \\
\text { and } \# 2\end{array}$ \\
\hline & & $1.5 \times 10^{14} \mathrm{Pas}$ for flow law $\# 3$ \\
\hline & $\sigma_{\mathbf{u}}$ & $50 \mathrm{~m} / \mathrm{a}$ \\
\hline & $\sigma_{\mathrm{A}}$ & $0.02 \mathrm{~m} / \mathrm{a}$ ice equivalent \\
\hline
\end{tabular}

*Data sources: Bentley and others, 1979; Clausen and others, 1979; Shabtaie and Bentley, 1987; paper in preparation by R.A. Bindschadler and others.

and, along with segment-by-segment break-downs of contributions from individual segments of $\Gamma$, in Figures 4 and 5. Form drag $\boldsymbol{F}^{\mathrm{f}}$, which arises because of non-uniformity of ice thickness, is clearly the dominant term of the total force budget. If the ice thickness were constant, the form drag would be exactly zero (assuming a spatially homogeneous firn layer). As shown in Figure 3, the ice thickness is greater up-stream of the ice-rise complex than down-stream, and is greater on the southern flank than on the northern. The form drag $\boldsymbol{F}^{\mathrm{f}}$ is thus diverted approximately $45^{\circ}$ from alignment with the regional flow of the ice shelf. This indicates that forces generated by the ice rise do not entirely depend on the direction of flow. In the present circumstance, the ice rise acts to maintain thicker ice along the Transantarctic Mountains in addition to resisting the glaciostatic push of the ice streams.

Dynamic drags $F^{\mathrm{d}}$ (Table IV; Fig. 5) computed using the three alternative flow laws presented in Table II exhibit similar magnitude and direction. This similarity suggests that conclusions drawn from our analysis are relatively insensitive to flow-law uncertainty. The magnitudes of the three

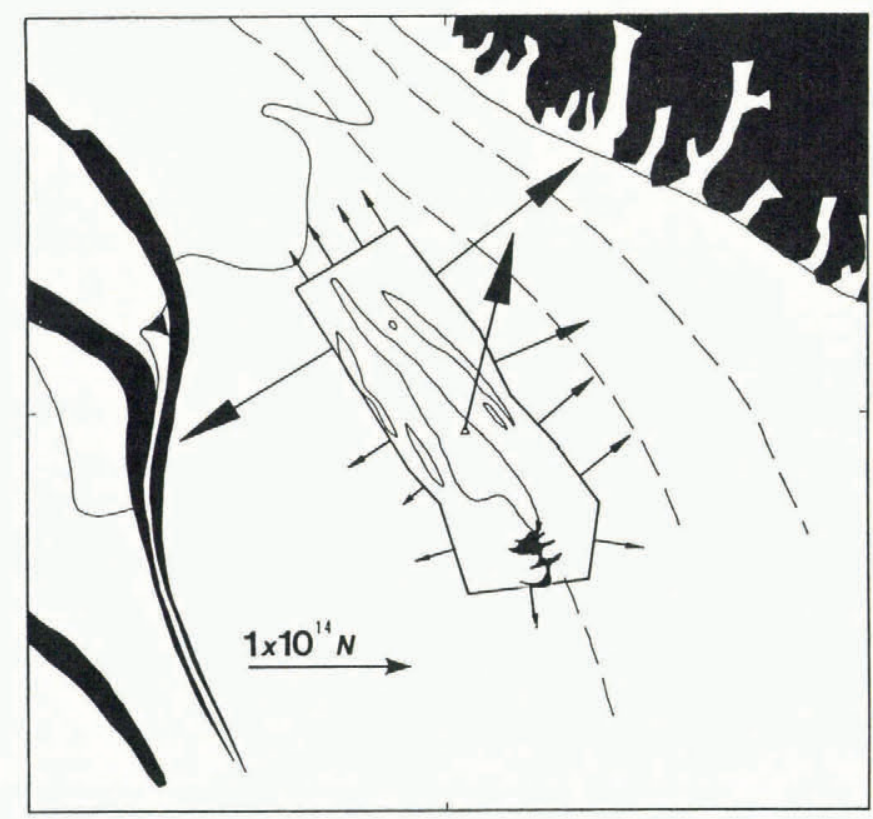

Fig. 4. Form drag plotted for each boundary segment. Net plotted at station $E_{\mathbf{4}}$.

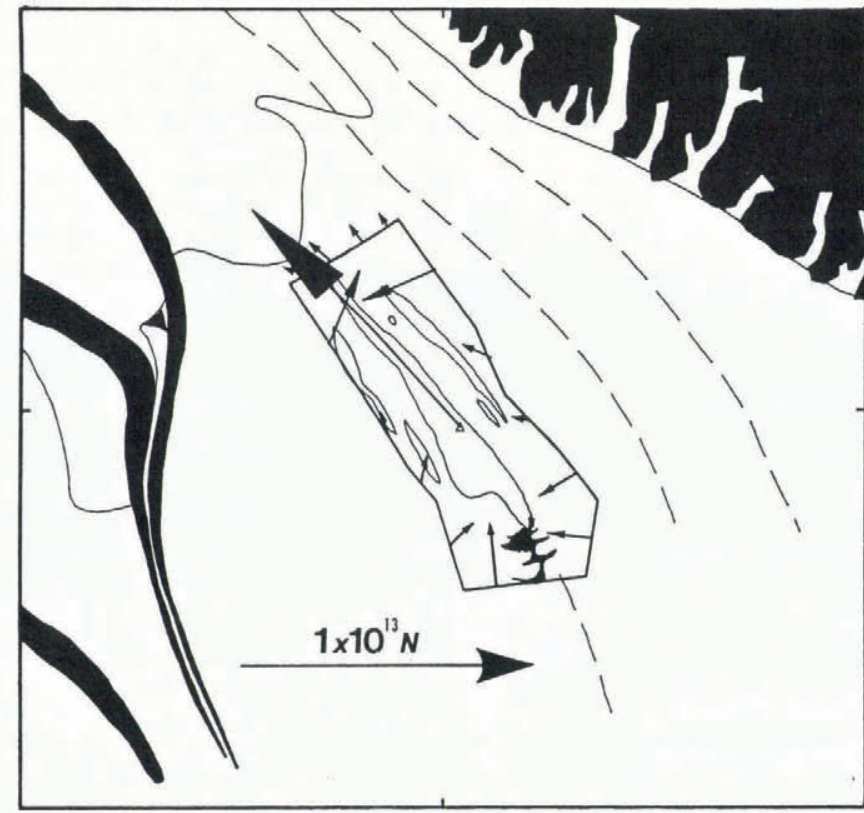

Fig. 5. Dynamic drag computed using flow law \#I (Table III) plotted for each boundary segment (note different scale than Figure 4). Net plotted at station $E_{4}$.

alternative dynamic drags are 8,7 , and $5 \%$, for flow laws \#1 to 3 , respectively, of the magnitude of the form drag. Unlike the form drag, the dynamic drag is aligned against the regional flow (Fig. 5) as expected for a purely frictional resistance.

Studies of large-scale ice-shelf flow have suggested that shear faults, or boundary zones of substantial ice failure, may exist on shear margins where the ice shelf flows past stagnant, grounded ice (MacAyeal and others, 1986). The strain-rate and velocity measurements reported here are not from surface stations sufficiently close to the ice-rise perimeter to verify this hypothesis (see, however, other measurements taken during 1983-85 reported by Bindschadler and others (paper in preparation)). Analysis of the dynamic drag acting on different parts of $\Gamma$ may indicate, however, which orientations of the ice-rise boundary with respect to the surrounding flow yield the greatest friction.

Segment-by-segment break-down of $F^{d}$ computed using flow law $\# 1$ as a standard of comparison (shown in Figure 5) reveals that the up-stream and down-stream ends of $\mathrm{I}_{(}\left(\mathrm{C}_{2}\right.$ to $\mathrm{G}_{2}$ and $\mathrm{J}_{10}$ to $\mathrm{I}_{11}$, respectively) contribute more to $F^{d}$ than do the flanks $\left(C_{2}\right.$ to $J_{10}$ and $I_{11}$ to $\left.C_{2}\right)$, whose individual contributions to the transverse component of $F^{d}$ tend to cancel. The dominant influence of the up-stream and down-stream ends of the ice-rise complex can be explained in terms of the observed strain-rate patterns shown in Figures 6 and 7. Up-stream of the ice-rise complex, the most compressive principal axis of the horizontal strain-rate tensor is oriented perpendicular to $r$, whereas down-stream of the ice-rise complex, the most tensile axis is perpendicular to $\Gamma$. This combination of orientations on the up-stream and down-stream sides produces the majority of the net dynamic drag. Shear stress along the flanks of the ice-rise complex is relatively weak (outside of the perimeter of $\Gamma$ ). Tangential contributions to $F$ d thus tend to be small.

\section{FORM DRAG AND DYNAMIC DRAG: INTERPRET- ATION}

The significance of the bulk-force budget calculated for the Crary Ice Rise complex is best illustrated by comparing the force computed above with the imaginary force that would exist if the region enclosed by $\Gamma$ were replaced with a sea-water-filled cavity. In this circumstance, the net force transmitted through $\Gamma$ is entirely due to sea-water pressure and is given by 
TABLE IV. DERIVED BUDGETS ${ }^{(1)}$

\section{Budget}

Form drag

$F^{f}$
$\mid F^{f}$

Dynamic drag

Effective resistance
Energy dissipation
Advective mass flux
Snow accumulation
Net mass balance

Apparent thickening rate

Form drag

$\begin{array}{cc}F^{\mathrm{f}} x^{*} & \text { Al } \\ F^{\mathrm{f}} y^{*} & \text { Al } \\ \left|F^{\mathrm{f}}\right|^{*} & \text { Al }\end{array}$

Dynamic drag

$$
\begin{gathered}
F_{x}^{\mathrm{d}} x^{*} \\
F^{\mathrm{d}} y^{*} \\
\left|F^{\mathrm{d}}\right|^{*}
\end{gathered}
$$

Extra back-pressure

force

$\left(F^{\mathrm{f}}+F^{\mathrm{d}}-F^{\mathrm{w}}\right) x^{*}$

$\left(F^{\mathrm{f}}+F^{\mathrm{d}}-F^{\mathrm{w}}\right) y^{*}$

$\left|F^{\mathrm{f}}+F^{\mathrm{d}}-F^{\mathrm{w}}\right| *$

Energy dissipation

Ice discharge

$W^{*}$

$Q^{*}$

$\begin{array}{rl}F_{x}^{\mathrm{i}}{ }^{\mathrm{c}} & \mathrm{A} 1 \\ F^{\mathrm{i}}{ }^{\mathrm{c}} & \mathrm{A} 1 \\ \left|F^{\mathrm{i}}\right|^{\mathrm{c}} & \mathrm{A} 1\end{array}$

Dynamic drag ${ }^{(3,4)}$

Form drag

$F_{x}^{\mathrm{d}}{ }_{x}^{\mathrm{c}}$

$F_{y}^{\mathrm{d}} \mathrm{c}$

$\left|F^{\mathrm{d}}\right| \mathrm{c}$

Effective resistance

$$
\begin{aligned}
& \left(F^{\mathrm{f}}+F^{\mathrm{d}}-F^{\mathrm{w}}\right)_{x} \mathrm{c} \\
& \left(F^{\mathrm{f}}+F^{\mathrm{d}}-F^{\mathrm{w}}\right)_{y}^{\mathrm{c}} \\
& \left|F^{\mathrm{f}}+F^{\mathrm{d}}-F^{\mathrm{w}}\right|^{\mathrm{c}}
\end{aligned}
$$

A10-A11

Analysis
formula

A1

Al

Al

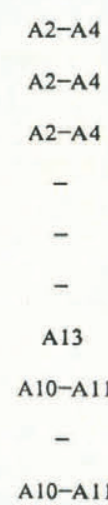

A10-Al1

Al

A1

Al

A2-A4

A2-A4

A2-A4
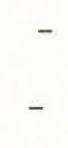

A 13

A1

A. 1

A1

A2-A4

A2-A4

A2-A4

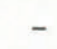

$-$

$$
\begin{gathered}
\text { Value(s) } \\
\text { Contour } r \\
(9.56 \pm 0.62) \times 10^{13} \\
(8.14 \pm 0.19) \times 10^{13} \\
(12.56 \pm 0.49) \times 10^{13} \\
\text { Flow law } \# 2
\end{gathered}
$$

Flow law \# 1

Flow law 3

Units

Uncertainty

fornula

$(-0.13 \pm 0.03) \times 10^{13}(-0.12 \pm 0.03) \times 10^{13}(0.07 \pm 0.02) \times 10^{13} \mathrm{~N}$

A6-A9

A6-A9

A6-A9

A5-A $9^{(2)}$

$(1.06 \pm 0.04) \times 10^{13}(0.92 \pm 0.04) \times 10^{13}(0.69 \pm 0.03) \times 10^{13} \mathrm{~N}$

A5-A9(2)

$(1.81 \pm 0.02) \times 10^{13}(1.74 \pm 0.02) \times 10^{13}(1.49 \pm 0.02) \times 10^{13} \mathrm{~N}$

$\mathrm{A} 5-\mathrm{A} 9^{(2)}$

$(2.02 \pm 0.07) \times 10^{13}(1.95 \pm 0.07) \times 10^{13}(1.85 \pm 0.07) \times 10^{13} \mathrm{~N}$

$\mathrm{A} 5-\mathrm{A} 9^{(2)}$

$(7.89 \pm 0.07) \times 10^{8} \quad(6.33 \pm 0.07) \times 10^{8} \quad(2.35 \pm 0.07) \times 10^{8} \mathrm{~W}$

A 14

$(1.06 \pm 0.19) \times 10^{5}$

$\mathrm{kg} \mathrm{s}^{-1}$

A 12

$(0.33 \pm 0.06) \times 10^{5}$

$\mathrm{kg} \mathrm{s}^{-1}$

$(1.40 \pm 0.20) \quad 10^{5}$

$\mathrm{kg} \mathrm{s}^{-1}$

$0.44 \pm 0.06$

$\mathrm{m}_{\text {year }}{ }^{-1}$

Contour $\Gamma^{*}$

$(3.59 \pm 0.14) \times 10^{13}$

N

A5

$(36.13 \pm 1.33) \times 10^{13}$

A5

$(36.30 \pm 1.33) \times 10^{13}$

As

\section{Flow law \#I}

Flow law \#2

Flow law *3

$(-0.26 \pm 0.03) \times 10^{13} \quad(-0.23 \pm 0.03) \times 10^{13}(-0.18 \pm 0.02) \times 10^{13} \mathrm{~N}$

A6-A9

$(0.10 \pm 0.05) \times 10^{13} \quad(0.09 \pm 0.05) \times 10^{13}(0.18 \pm 0.04) \times 10^{13} \mathrm{~N}$

AG-A9

A6-A9

$\mathrm{A} 5-\mathrm{A} 9^{(2)}$

$\mathrm{A} 5-\mathrm{A} 9^{(2)}$

$(4.04 \pm 0.13) \times 10^{13}(3.85 \pm 0.13) \times 10^{13}(4.12 \pm 0.13) \times 10^{13} \mathrm{~N}$

$\mathrm{A} 5-\mathrm{A} 9^{(2)}$

$(4.04 \pm 0.13) \times 10^{13}$

$(3.85 \pm 0.13) \times 10^{13}(4.13 \pm 0.13) \times 10^{13} \mathrm{~N}$

A 14

A 12

$(13.65 \pm 0.42) \times 10^{5} \quad \mathrm{~kg} \mathrm{~s}^{-1}$

$$
\text { Contour } \Gamma^{c}
$$

$(3.89 \pm 5.22) \times 10^{12}$

A5

$(-2.24 \pm 4.66) \times 10^{12}$

A5

$(4.49 \pm 7.00) \times 10^{12}$

A5

Flow law \#1

Flow law \#2

Flow law 3

$(0.75 \pm 4.98) \times 10^{11}$

N

A6-A9

$(5.25 \pm 3.96) \times 10^{11}$

A6-A9

A6-A9

$(5.31 \pm 6.36) \times 10^{11}$

A5-A $9^{(2)}$

$(0.49 \pm 0.72) \times 10^{12}$

$(0.28 \pm 0.61) \times 10^{12}$

$\mathrm{A} 5-\mathrm{A} 9^{(2)}$

A5-A $9^{(2)}$

(1) Horizontal coordinate axes $x$ and $y$ comprise a loçal rectangular reference frame in a polar stereographic projection of our field area. $x$ and $y$ extend along true azimuths $225^{\circ}$ and $135^{\circ}$, respectively, from station $\mathrm{E}_{4}$ (Fig. 2) taken as the origin.

${ }^{(2)}$ Uncertainty of $F^{f}-F^{\mathrm{w}}$ is taken to be $\left(1-\rho_{\mathrm{i}} / \rho_{\mathrm{w}}\right)$ times the uncertainty of $F^{\mathrm{f}}$.

${ }^{(3)}$ For brevity, and in view of the insignificant results, we only use flow law $\# 1$ in the control experiment. Flow laws $\sharp 2$ and $\sharp 3$ would yield even less significant values.

(4) $\bar{B}^{z}$ was increased to $1.9 \pm 0.2 \times 10^{8} \mathrm{~Pa} \mathrm{~s}^{1 / 3}$ to account for cooler ice in the vicinity of the ice front (see Thomas and MacAyeal, 1982). 


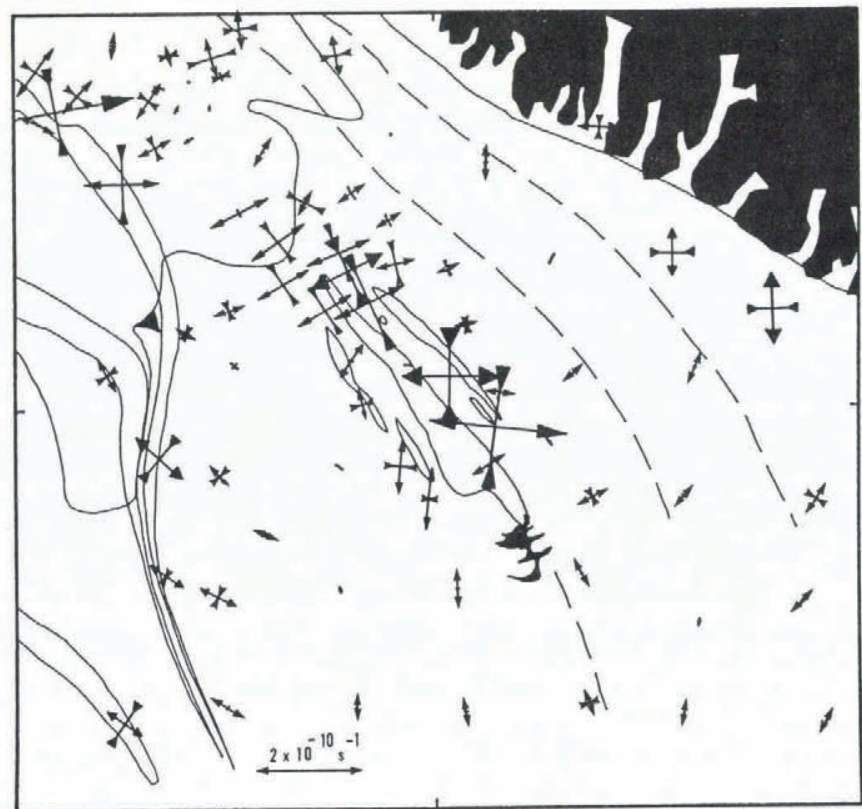

Fig. 6. Surface strain-rates (principal axes) at selected stations (Thomas and others, 1984; Bindschadler and others, 1987, in press). See also Table I.

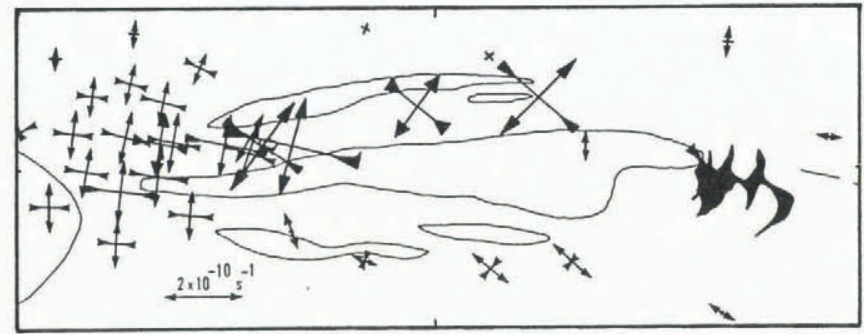

Fig. 7. Surface strain-rates (principal axes) in detail around the Crary Ice Rise complex.

$$
F^{\mathrm{W}}=\int_{\Gamma^{2}} \frac{1}{\rho_{\mathrm{W}}}\left\{\rho_{\mathrm{i}} H+\frac{\alpha}{\beta}\left(1-\mathrm{e}^{\beta H}\right)\right\}^{2} n \mathrm{~d} \lambda
$$

where $\rho_{w}=1028 \mathrm{~kg} / \mathrm{m}^{3}$ is the density of sea-water. Note that $\boldsymbol{F}^{\mathrm{w}}$ is also the net horizontal component of the force that would be exerted against the bottom of the ice within $\Gamma$ if it were entirely afloat. We computed $F^{\mathrm{W}}$ using the same procedure used to compute $\boldsymbol{F}^{\mathrm{f}}$ outlined in the Appendix, and present the result in Table IV.

The magnitude of $\boldsymbol{F}^{\mathrm{w}}$ amounts to approximately $90 \%$ of the form drag $F^{f}$; thus the vector difference $\left(F^{\mathrm{f}}+F^{\mathrm{d}}-F^{\mathrm{w}}\right)$ is considerably smaller in magnitude than the total force $\left(F^{\mathrm{f}}+F^{\mathrm{d}}\right)$ transmitted through $\Gamma$. The difference $\left(F^{\mathrm{f}}+F^{\mathrm{d}}-F^{\mathrm{w}}\right)$, shown in Table IV and in Figure 8 , is the part of the total force resulting from grounding within $\Gamma$. We refer to $\left(F^{\mathrm{f}}+F^{\mathrm{d}}-F^{\mathrm{w}}\right)$ as the effective resistance of the ice-rise complex because it constitutes the part of the total force that arises due to friction associated with ice/sea-bed contact.

Detailed analysis of the stress continuity equations (see MacAyeal and others, 1986; Morland, 1987) reveals that the effective resistance of an ice-rise-free part of the ice shelf must vanish. The difference between $F^{\mathrm{f}}$ and $F^{\mathrm{w}}$ produces the driving force which causes the ice shelf to spread. This difference leads directly to the longitudinal deviatoric stress and thus to $F^{\mathrm{d}}$. It follows that $\left(\boldsymbol{F}^{\mathrm{f}}+\boldsymbol{F}^{\mathrm{d}}+\boldsymbol{F}^{\mathrm{w}}\right)$ should equal 0 across any floating section of the ice shelf if there is no resistance to spreading except for the water. We confirm this interpretation in a control experiment described in the next section. The only physical change within the contour $\lceil$ which could reduce the effective resistance to zero is the elimination of grounded ice. The effective

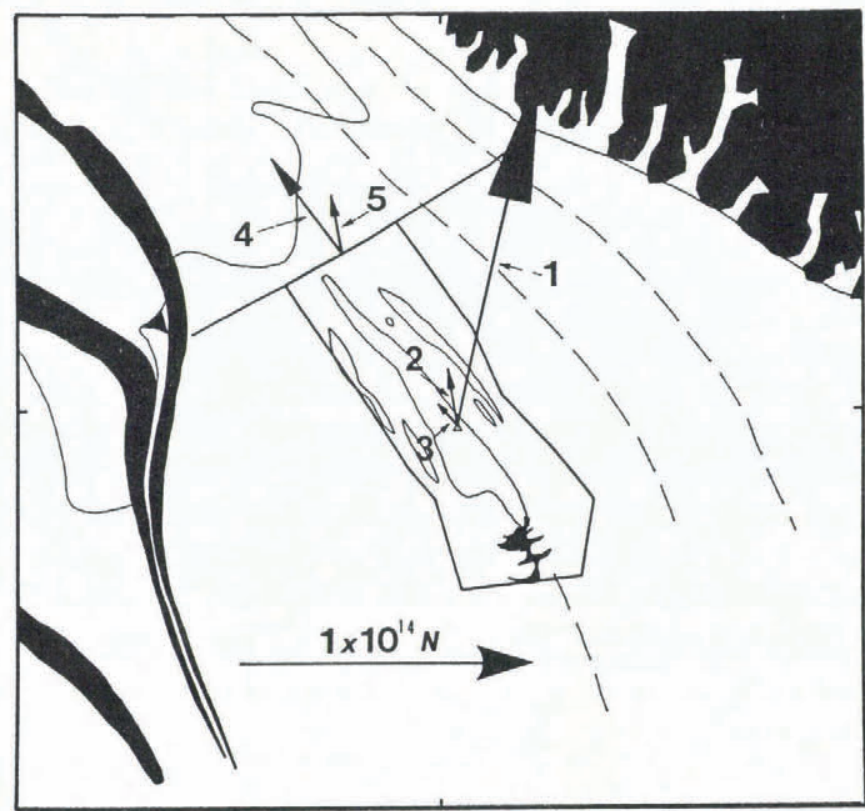

Fig. 8. Net-force vectors representing the effective resistance of the Crary Ice Rise complex on its surroundings, and the extra back-pressure force transmitted through the ice-stream gateway (computed using flow law \#1; Table III). (1) $\boldsymbol{F}^{f}$ on $\Gamma$; (2) $\left(\boldsymbol{F}^{f}+\boldsymbol{F}^{d}-\boldsymbol{F}^{w}\right)$ on $\Gamma_{\text {; }}$ (3) $\boldsymbol{F}^{d}$ on $\Gamma^{i}$ (4) $\left(\boldsymbol{F}^{f}+\boldsymbol{F}^{d}-\boldsymbol{F}^{w}\right)$ on $\Gamma^{*} ;$ (5) $\left(\boldsymbol{F}^{f}+\boldsymbol{F}^{d}-\boldsymbol{F}^{w}\right)$ on $\Gamma$ (same as (2) above).

resistance thus represents the part of the total ice-rise force that is sensitive to changing basal-contact area. This resistance can also be identified as the part of the total force most sensitive to climatic change.

Significance of the effective resistance generated by the ice-rise complex may be judged in terms of the force $\left(F^{\mathrm{f}}+F^{\mathrm{d}}-F^{\mathrm{w}}\right)^{*}$ transmitted across the grounding line of Ice Streams $\mathrm{A}$ and $\mathrm{B}$ through the contour $\Gamma^{*}$ (shown in Figure 1). We refer to $\left(F^{\mathrm{f}}+\boldsymbol{F}^{\mathrm{d}}-\boldsymbol{F}^{\mathrm{W}}\right)^{*}$ as the extra back-pressure force (Thomas, 1979[b]) because it represents resistance generated by the entire ice shelf above that provided by sea-water pressure acting alone on the ice front and sloping under side of the ice shelf.

We computed the extra back-pressure force acting across $\Gamma^{*}$ using the same procedure as used to calculate the effective resistance of the ice-rise complex. The effective resistance produced by the Crary Ice Rise complex is found to vary between 45 and $51 \%$ of the extra back-pressure force, depending on the flow law used to calculate dynamic drag (Table IV and Fig. 8). The ice-rise complex thus provides a significant restraint on the flow of Ice Streams A and $\mathrm{B}$, and this result is relatively insensitive to flow-law uncertainties.

Another interpretation of the effective resistance $\left(\boldsymbol{F}^{\mathrm{f}}+\right.$ $\left.F^{\mathrm{d}}-\boldsymbol{F}^{\mathrm{w}}\right)$ may be made in terms of an equivalent basal shear stress $\tau_{b}$, defined as the magnitude of the effective resistance divided by the estimated area of grounded ice contained within $\Gamma\left(2.0 \times 10^{9} \mathrm{~m}^{2}\right)$. The value of $\tau_{\mathrm{b}}$ ranges between $0.045 \times 10^{5} \mathrm{~Pa}$ and $0.1 \times 10^{5} \mathrm{~Pa}(0.045-0.1$ bar), depending on the flow law. This range is comparable to regional averages of the longitudinal component of basal stress computed using the balance expression $\tau_{\mathrm{b}}=\rho_{\mathrm{i}} g H \gamma$, surface slopes $\gamma$ ranging between $0.9 \times 10^{-3}$ and $2.0 \times 10^{-3}$, and an area-average ice thickness $H=550 \mathrm{~m}$. An idealization of ice-rise resistance in terms of an effective basal shear stress may prove useful in predictive models of ice-shelf dynamics which cannot spatially resolve the details of flow surrounding small-scale ice rises.

\section{CONTROL EXPERIMENT}

To test our data-analysis procedure and to verify our interpretations, we computed the effective resistance $\left(\boldsymbol{F}^{\mathrm{f}}+\right.$ $\left.F^{\mathrm{d}}-\boldsymbol{F}^{\mathrm{w}}\right)^{\mathrm{c}}$ for an ice-rise-free part of the Ross Ice Shelf 
enclosed by the control contour $\Gamma^{c}$ constructed by linking six RIGGS stations located near the ice front (Table I; Thomas and others, 1984). If our procedure and interpretations are correct, and if $\Gamma^{c}$ encloses floating ice shelf alone, $\left(\boldsymbol{F}^{\mathrm{f}}+\boldsymbol{F}^{\mathrm{d}}-\boldsymbol{F}^{\mathrm{w}}\right)^{\mathrm{c}}$ should be zero (or within the estimated uncertainty interval surrounding zero). As shown in Table IV, the effective resistance computed for $\Gamma^{c}$ is within estimated uncertainty of zero. This test confirms our data-analysis procedure and verifies that effective resistance is a valuable measure of ice-rise/ice-shelf interaction.

\section{MASS BALANCE}

Mass balance, $M\left(\mathrm{~kg} \mathrm{~m}^{-3}\right)$, of the region enclosed by $\Gamma$ was computed under the assumption that basal melting is zero. In this circumstance, $M$ is the sum of advection, denoted $Q$, and snow accumulation $\dot{A}\left(\mathrm{~kg} \mathrm{~m}^{-2} \mathrm{~s}^{-1}\right)$, and is given by

$$
M=-\oint_{\Gamma}\left(\rho_{\mathrm{i}} H+\frac{\alpha}{\beta}\left(1-\mathrm{e}^{\beta H}\right)\right) \boldsymbol{u} \cdot \boldsymbol{n} \mathrm{d} \lambda+\int_{S} \int \dot{A} \mathrm{~d} x \mathrm{~d} y
$$

where $u\left(\mathrm{~m} \mathrm{~s}^{-1}\right)$ is the horizontal ice velocity (independent of depth at our ice-shelf measurement stations; see Morland, in press), and $S$ is the surface area enclosed by $\Gamma(1.1065 \times$ $10^{10} \mathrm{~m}^{2}$ on the stereographic projection using station $E_{4}$ as the projection pole). We computed $M$ using the following data: (i) the regionally averaged snow-accumulation rate determined by beta-activity analysis of snow cores from ten RIGGS stations $\left(F_{7}, G_{8}, G_{10}, H_{8}, H_{9}, H_{10}, H_{11}, I_{9}, I_{10}\right.$, and $I_{11}$ ) reported by Clausen and others (1979); (ii) linearly interpolated values of $u$ using the observed values of $u$ at surface stations along $\Gamma$ (Fig. 9; Table I); and (iii) ice thickness $H$ derived from radio echo-sounding flights (or interpolated from RIGGS measurements over segments $\mathrm{K}_{3}$ to $J_{10}, J_{11}$ to $I_{11}$, and $I_{11}$ to $J_{3}$ ). The discretized version of the contour integral in Equation (15) used to calculate $M$ is presented in the Appendix. Confidence limits on $M$ are calculated using estimated uncertainties of the velocity component perpendicular to $\Gamma$ and of $\dot{A}$ shown in Table III.

The computed mass balance $M$ indicates that mass is accumulating within $\Gamma$ at a rate of $1.40 \pm 0.20 \times 10^{5} \mathrm{~kg} \mathrm{~s}^{-1}$.

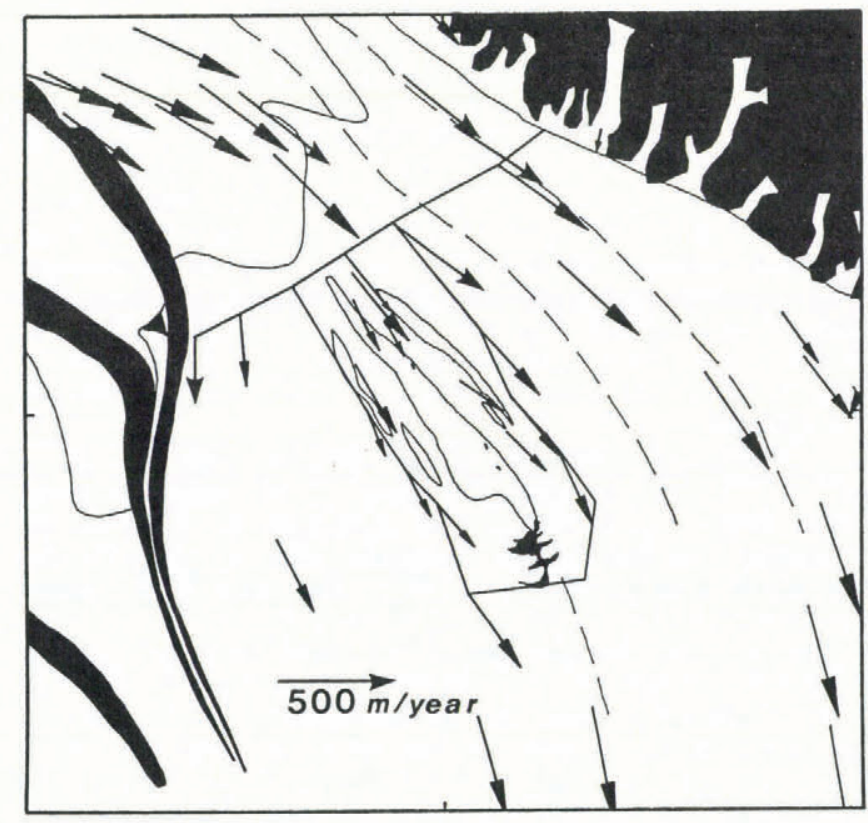

Fig. 9. Measured surface velocities used to calculate mass balance and the work done against resistive forces of the Crary complex (see also Table I). Data sources: Bindschadler and others (1984); Thomas and others (1984); Bindschadler and others (1987); paper in preparation by R.A. Bindschadler and others. All measurements were conducted using "geoceiver" satellite position-fixing equipment.
This accumulation could be balanced in part, or in whole, by basal melting (at an average rate of $0.44 \mathrm{~m} /$ year) within $\Gamma$ (see Pillsbury and Jacobs (1985) for discussion of oceanic evidence for basal melting below the Ross Ice Shelf). Given the lack of sub-ice-shelf ablation measurements available from the Ross Ice Shelf, it is not possible to judge the likelihood of such a balance. MacAyeal (1984) suggested, however, that tidal fronts may develop in the sea-water cavity surrounding Crary Ice Rise as a result of high tidal amplitudes and vertical mixing. These fronts could promote locally vigorous basal melting at rates between 0.05 and $0.5 \mathrm{~m} /$ year. Our radio echo-sounding data indicate that basal echoes are strong in the vicinity of the ice rise, indicating possible basal erosion (see also Neal, 1979). Strongest basal-echo amplitudes occur along the southern flank of the ice-rise complex facing the Transantarctic Mountains. A sea-bed trough is situated adjacent to this flank, and may provide a path for warm, saline water to penetrate from sources in the open Ross Sea (MacAyeal, 1984; see Greischar and Bentley (1980) for a map of sub-ice-shelf sea-bed elevation). If tidally triggered basal melting is active in the vicinity of the ice-rise complex, it is unlikely to affect more than a limited part of the area enclosed within $\Gamma$ (MacAyeal, 1984). We therefore suggest that $M$ is largely unbalanced by basal ablation.

Assuming that basal melting does not balance $M$, mass accumulation within $\Gamma$ would support an area-average thickening rate of $0.44 \pm 0.06 \mathrm{~m} /$ year. This apparent thickening rate is consistent with previous estimates of mass balance (Thomas, 1976; Thomas and Bentley, 1978; Jezek and Bentley, 1984; Shabtaie and Bentley, 1987), and suggests that the ice-rise complex is growing. To test this suggestion, the temperature-depth profile could be measured at a number of positions on the grounded ice rise to see whether deviations from steady state support a history of recent grounding. This procedure was used to date the formation of ice rises on Ward Hunt Ice Shelf in the Arctic Ocean (Lyons and others, 1972; see also MacAyeal and Thomas, 1980).

For reference, we also computed the net mass discharge, $Q^{*}$, of Ice Streams $A$ and $B$ into the Ross Ice Shelf across the contour $\Gamma^{*}$. The apparent mass accumulation within the ice-rise complex $M$ (Table IV) amounts to $10 \%$ of the net ice-stream discharge (Table IV). Our computed value of $Q^{*}$, in terms of ice volume, amounts to $46.9 \pm$ $1.4 \mathrm{~km}^{3} /$ year. Given the uncertainty, this value is equivalent to $49.2 \pm 2.5 \mathrm{~km}^{3} /$ year reported by Shabtaie and Bentley (1987) for a slightly different cross-section of the ice-stream grounding line (see fluxes A, B, and B2 in their table 2a).

Shabtaie and Bentley (1987) suggest that the present mass flux of Ice Stream B exceeds snow catchment in the region drained by the ice stream by approximately $10-20 \mathrm{~km}^{3}$ /year (see their table 2c). If their estimate is correct, then approximately $25-50 \%$ of the excess discharge could be accumulating within the ice-rise complex or balanced by basal melting there. The current vigorous flow of Ice Streams A and B may thus be building ice rises.

\section{MECHANICAL-ENERGY BUDGET}

Gravitational potential energy must be released in the ice-shelf/ice-stream system to balance energy loss associated with flow past the ice-rise complex. This energy loss results from: (i) work done against friction (dynamic drag), and (ii) redistribution of gravitational potential energy associated with ice-shelf or ice-rise thickening within $Г$. In computing the redistribution of potential energy, it is necessary to account for potential energy associated with displaced seawater. We compute the energy loss by evaluating the rate at which work is done along $\Gamma$ by ice-shelf movement against the effective resistance:

$$
W=\oint_{\Gamma} u \cdot\left(f^{\mathrm{f}}+f^{\mathrm{d}}-f^{\mathrm{w}}\right) \mathrm{d} \lambda
$$

where $\left(f^{f}+f^{d}-f^{w}\right)$ is the local equivalent of the effective resistance. 
Work done against the local form drag $f^{\text {f }}$ represents the rate at which gravitational potential energy possessed by ice is carried by advection across Г. This flux exists only where there is net mass influx across $\Gamma$ (see previous section). Archimedes' principle requires that, for a given ice-shelf mass entering $r$, an equal sea-water mass must flow out of $\Gamma$. This requirement assumes that sea-level changes negligibly as a result of mass convergence into $r$, and that ice-shelf flux convergence leads to ice-shelf thickening rather than ice-rise thickening. Gravitational potential energy flux associated with this displaced sea-water mass is smaller than that of the equal mass of ice; and is equal in magnitude, but opposite in sign, to the work done by ice shelf against hydrostatic sea-water pressure $f^{\mathrm{W}}$ along $\Gamma_{f}$ Work done by the ice shelf against the difference $f^{\mathrm{f}}-f^{\mathrm{w}}$ thus represents the net potential energy change within $\Gamma$ due to mass exchange between water and ice. Work done against dynamic drag $f^{d}$ along the contour i accounts for frictional energy dissipation. Values of $W$ computed using the data-analysis procedures presented in the Appendix and the three alternative flow laws are presented in Table IV.

Energy loss within the ice-rise complex may originate up-stream of the grounding line where ice-stream thinning releases gravitational potential energy. In this circumstance, energy must be transferred to the ice shelf by work done at the ice-stream grounding lines. We examine this possibility by computing the work $W^{*}$ done against the extra back-pressure force $\left(f^{\mathrm{f}}+f^{\mathrm{d}}-f^{\mathrm{w}}\right)$ by Ice Streams A and $B$ along the grounding-line contour $\Gamma^{*}$. This work accounts for energy losses associated with resistance provided by the entire ice shelf. As shown in Table IV, the energy loss associated with the ice-rise complex $W$ is found to range between 15 and $49 \%$ of the grounding-line energy flux $W^{*}$ (for flow laws $\# 3$ and $\# 1$, respectively). This result suggests that the ice-rise complex provides a substantial sink of potential energy released by ice-stream flow.

\section{ICE-RISE, ICE-SHELF, AND ICE-STR.EAM INTER- ACTIONS}

Our interpretation of field data yields the following conclusions: (i) approximately $45-51 \%$ of the extra backpressure force on the grounding line of Ice Streams A and $B$ results from the effective resistance generated by the Crary Ice Rise complex; (ii) the fraction of this extra backpressure force contributed by the ice-rise complex is relatively insensitive to the flow law used to convert measured strain-rate into stress; (iii) the effective ice-rise resistance varies by a factor of two between non-Newtonian flow laws $(n=3)$ commonly used in analysis of ice-shelf flow (such as derived from laboratory creep tests by Barnes and others (1971), or from bore-hole tilt and ice-shelf spreading observations by Paterson (1981) and the Newtonian flow law $(n=1)$ described by Doake and Wolff (1985[a], [b])); (iv) ice accumulates within the ice-rise complex, primarily due to ice-flow convergence, at a rate exceeding estimates of regional basal melting derived from MacAyeal (1984) and from Pillsbury and Jacobs (1985); (v) if this accumulation is not balanced by basal melting, the ice-rise complex may be expanding through ice-shelf thickening and grounding; (vi) this possible expansion may constitute a response to high discharge through Ice Streams A and B; and (vii) energy dissipated by flow around the ice-rise complex is balanced by energy transmitted across the grounding line of Ice Streams A and B.

Considering the possible consequences of climatic change such as atmospheric warming, oceanic warming, or sea-level rise, our analysis supports the view expressed by Thomas and others (1979) that ice rises and ice rumples are key sources of resistance that stabilize the West Antarctic ice sheet. Ice-rise influence is large compared with the physical size of the ice rise or rumple; thus, relatively local changes of oceanic or atmospheric conditions in the vicinity of an ice rise or rumple may produce widespread modifications of the ice-sheet/ice-shelf system. In terms of ice-stream dynamics, our results suggest that ice rises may form or expand in response to ice-stream accelerations and, given time to develop significant resistance, may ultimately damp the ice-stream fluctuations that formed them.

\section{ACKNOWLEDGEMENTS}

We thank A.P. Crary, I. Whillans, and R.H. Thomas for helping plan the field program presented here. The efforts of the following field assistants were crucial in gathering the data reported here: H.J. Zwally, J. Scofield, D. Lindstrom, J. Foster, E. Roberts, M. Sturm, and J. Dahlman. G. York typed and edited the manuscript. I. Whillans and the referees provided valuable comments. Funding for this project was provided by N.S.F. grants DPP 8120332 , DPP 8412404, DPP 8207320, DPP 8405287, DPP 8514543; NASA grant NAG 5-394, and the Charles A. Lindbergh Fund.

\section{REFERENCES}

Barnes, P., and others. 1971. The friction and creep of polycrystalline ice, by P. Barnes, D. Tabor, and J.C.F. Walker. Proceedings of the Royal Society of London, Ser. A, Vol. 324, No. 1557, p. 127-55.

Bentley, C.R. 1984. The Ross Ice Shelf Geophysical and Glaciological Survey (RIGGS): introduction and summary cf measurements performed. (In Hayes, D., and Bentley, C.R., eds. The Ross Ice Shelf: glaciology and geophysics. Washington, DC, American Geophysical Union, p. 1-20. (Antarctic Research Series, Vol. 42.))

Bentley, C.R., and others. 1979. Ice-thickness patterns and the dynamics of the Ross Ice Shelf, Antarctica, by C.R. Bentley, J.W. Clough, K.C. Jezek, and S. Shabtaie. Journal of Glaciology, Vol. 24, No. 90, p. 287-94.

Bindschadler, R.A., and others. 1987. Ice stream-ice shelf interaction in West Antarctica, by R.A. Bindschadler, D.R. MacAyeal, and S.N. Stephenson. (In Veen, C.J. van der, and Oerlemans, J., eds. Dynamics of the West Antarctic ice sheet; proceedings of a workshop held in Utrecht, May 6-8, 1985. Dordrecht, etc., D. Reidel Publishing Company, p. 161-80.)

Bindschadler, R.A., and others. In press. Ice dynamics at the mouth of Ice Stream B, Antarctica, by R.A. Bindschadler, S. Stephenson, D.R. MacAyeal, and S. Shabtaie. Journal of Geophysical Research.

Boas, M.L. 1983. Mathematical methods in the physical sciences. Second edition. New York, John Wiley and Sons.

Clausen, H.B., and others. 1979. Surface accumulation on Ross Ice Shelf, by H.B. Clausen, W. Dansgaard, J.O. Nielsen, and J.W. Clough. Antarctic Journal of the United States, Vol. 14 , No. 5 , p. 68-72.

Clough, J.W., and Hansen, B.L. 1979. The Ross Ice Shelf Project. Science, Vol. 203, No. 4379, p. 433-34.

Doake, C.S.M., and Wolff, E.W. 1985[a]. Flow law for ice in polar ice sheets. Nature, Vol. 314, No. 6008, p. 255-57.

Doake, C.S.M., and Wolff, E.W. 1985[b]. Reply [to Paterson, W.S.B., Flow law for ice in polar ice sheets]. Nature, Vol. 318 , No. 6041 , p. $82-83$.

Drewry, D.J., ed. 1983. Antarctica: glaciological and geophysical folio. Cambridge, University of Cambridge. Scott Polar Research Institute.

Greischar, L.L., and Bentley, C.R. 1980. Isostatic equilibrium grounding line between the West Antarctic inland ice sheet and the Ross Ice Shelf. Nature, Vol. 283, No. 5748, p. $651-54$.

Holdsworth, G. 1982. Dynamics of Erebus Glacier Tongue. Annals of Glaciology, Vol. 3, p. 131-37.

Hooke, R.L. 1981. Flow law for polycrystalline ice in glaciers: comparison of theoretical predictions, laboratory data, and field measurements. Reviews of Geophysics and Space Physics, Vol. 19, No. 4, p. 664-72.

Jaeger, J.C. 1969. Elasticity, fracture and flow. Third edition. London, Methuen. 
Jezek, K.C., and Bentley, C.R. 1984. A reconsideration of the mass balance of a portion of the Ross Ice Shelf, Antarctica. Journal of Glaciology, Vol. 30, No. 106, p. 381-84.

Kirchner, J.F., and others. 1979. Lateral density differences from seismic measurements at a site on the Ross Ice Shelf, Antarctica, by J.F. Kirchner, C.R. Bentley, and J.D. Robertson. Journal of Glaciology, Vol. 24, No. 90, p. 309-12.

Lliboutry, L., and Duval, P. 1985. Various isotropic and anisotropic ices found in glaciers and polar ice caps and their corresponding rheologies. Annales Geophysicae, Vol. 3, No. 2, p. 207-24.

Lyons, J.B., and others. 1972. Growth and grounding of the Ellesmere Island ice rises, by J.B. Lyons, R.H. Ragle, and A.J. Tamburi. Journal of Glaciology, Vol, 11, No. 61, p. $43-52$.

MacAyeal, D.R. 1984. Thermohaline circulation below the Ross Ice Shelf: a consequence of tidally induced vertical mixing and basal melting. Journal of Geophysical Research, Vol. 89, No. C1, p. 597-606

MacAyeal, D.R. 1987. Ice-shelf backpressure: form drag versus dynamic drag. (In Veen, C.J. van der, and Oerlemans, J., eds. Dynamics of the West Antarctic ice sheet; proceedings of a workshop held in Utrecht, May 6-8, 1985. Dordrecht, etc., D. Reidel Publishing Company, p. 141-60.)

MacAyeal, D.R., and Thomas, R.H. 1980. Ice-shelf grounding: ice and bedrock temperature changes. Journal of Glaciology, Vol. 25, No. 93, p. 397-400.

MacAyeal, D.R., and others. 1986. Formulation of ice shelf dynamic boundary conditions in terms of a Coulomb rheology, by D.R. MacAyeal, S. Shabtaie, C.R. Bentley, and S.D. King. Journal of Geophysical Research, Vol. 91, No. B8, p. 8177-91.

Morland, L.W., 1987. Unconfined ice-shelf flow. (In Veen, C.J. van der, and Oerlemans, J., eds. Dynamics of the West Antarctic ice sheet; proceedings of a workshop held in Utrecht, May 6-8, 1985. Dordrecht, etc., D. Reidel Publishing Company, p. 99-116.)

Neal, C.S. 1979. The dynamics of the Ross Ice Shelf revealed by radio echo-sounding. Journal of Glaciology, Vol. 24, No. 90, p. 295-307.

Paterson, W.S.B. 1981. The physics of glaciers. Second edition. Oxford, etc., Pergamon Press. (Pergamon International Library.)

Paterson, W.S.B. 1985. Flow law for ice in polar ice sheets, Nature, Vol. 318 , No. 6041, p. 82-83.

\section{APPENDIX}

We present the discretized equations used to evaluate the force, mass, and mechanical-energy budgets using our field data in Table A-I. All contour integrations on contours $\Gamma$ and $\Gamma^{*}$ were performed using the trapezoidal method (Young and Gregory, 1972, p. 363). Each of the 14 linear segments of $\Gamma$ (denoted by index $j$ ) was subdivided into $N_{j}-1$ sub-segments (denoted by index $k$ ) corresponding to points where the ice thickness $H_{k}$ was measured from the continuous radio echo-sounding flight records. Variables $\dot{e}_{k}$ and $u_{k}$ are the interpolated strain-rate and
Pillsbury, R.D., and Jacobs, S.S. 1985. Preliminary observations from long-term current meter moorings near the Ross Ice Shelf, Antarctica. (In Jacobs, S.S., ed. Oceanology of the Antarctic continental shelf. Washington, DC, American Geophysical Union, p. 87-108. (Antarctic Research Series, Vol. 43.))

Sanderson, T.J.O., and Doake, C.S.M. 1979. Is vertical shear in an ice shelf negligible? Journal of Glaciology, Vol. 22, No. 87 , p. $285-92$.

Shabtaie, S., and Bentley, C.R. 1982. Tabular icebergs: implications from geophysical studies of ice shelves. Journal of Glaciology, Vol. 28, No. 100, p. 413-30.

Shabtaie, S., and Bentley, C.R. 1987. West Antarctic ice streams draining into the Ross Ice Shelf: configuration and mass balance. Journal of Geophysical Research, Vol. 92, No. B2, p. 1311-36.

Thomas, R.H. 1976. Thickening of the Ross Ice Shelf and equilibrium state of the West Antarctic ice sheet. Nature, Vol. 259 , No. 5540 , p. $180-83$.

Thomas, R.H. 1979[a]. Ice shelves: a review. Journal of Glaciology, Vol. 24, No. 90 , p. 273-86.

Thomas, R.H. 1979[b]. The dynamics of marine ice sheets. Journal of Glaciology, Vol. 24, No. 90, p. 167-177.

Thomas, R.H., and Bentley, C.R. 1978. The equilibrium state of the eastern half of the Ross Ice Shelf. Journal of Glaciology, Vol. 20, No. 84, p. 509-18.

Thomas, R.H., and MacAyeal, D.R. 1982. Derived characteristics of the Ross Ice Shelf, Antarctica. Journal of Glaciology, Vol. 28, No. 100, p. 397-412.

Thomas, R.H., and others. 1979. Effect of climatic warming on the West Antarctic ice sheet, by R.H. Thomas, T.J.O. Sanderson, and K.E. Rose. Nature, Vol. 277, No. 5695, p. 355-58.

Thomas, R.H., and others. 1984. Glaciological studies on the Ross Ice Shelf, Antarctica, 1973-1978, by R.H. Thomas, D.R. MacAyeal, D.H. Eilers, and D.R. Gaylord. (In Hayes, D., and Bentley, C.R., eds. The Ross Ice Shelf: glaciology and geophysics. Washington, DC, American Geophysical Union, p. 21-53. (Antarctic Research Series, Vol. 42.))

Weertman, J. 1957. Deformation of floating ice shelves. Journal of Glaciology, Vol. 3, No. 21, p. 38-42.

Weertman, J. 1983. Creep deformation of ice. Annual Review of Earth and Planetary Sciences, Vol. 11, p. 215-40.

Whillans, I.M. 1987. Force budget of ice sheets. (In Veen, C.J. van der, and Oerlemans, J. eds. Dynamics of the West Antarctic ice sheet; proceedings of a workshop held in Utrecht, May 6-8, 1985. Dordrecht, etc., D. Reidel Publishing Company, p. 17-36.)

Young, D.M., and Gregory, R.T. 1972. A survey of numerical mathematics. Vol. 1. Reading, MA, AddisonWesley Publishing Co.

velocity at the $k^{\text {th }}$ position along the $j^{\text {th }}$ segment, and $\Delta \lambda k$ is the linear distance between points $k-1$ and $k$. Intermediate quantities used in the computation of the three budgets are also indicated in Table A-I. Uncertainties associated with the derived budgets are computed following the rules for determining experimental error of derived quantities summarized by Boas $(1983$, p. 734). Formulae used for computing these uncertainties are displayed in Table A-I, and the fundamental uncertainty estimates relating to measurement and interpolation error are displayed in Table III. 
TABLI: A-I. DATA-ANALYSIS IEORMULAE

Dirived atuantity

Form drag

Dynamic drag

Interpolated

strain-rate

( $p q$ component)

Effective depthaveraged viscosity

Second invariant of $\dot{c}_{k}$

$x$-component of the form drag uncertainty

$x$-component of the dynamic drag uncertainty

Uncertainty of $\bar{v}_{k} z$

Uncertainty of $\left.\dot{c}_{k}=\left(\frac{1}{2} \dot{c}_{i j} \dot{e}_{i j}\right)_{k}\right)^{\frac{1}{2}}$
Variable

Eipuation

number

$$
\left.+\frac{\alpha}{\beta^{2}} g\left[2-e^{\beta I I_{k-1}}-e^{\beta / I} k\right]\right\}
$$

$\mathbf{I}^{\mathrm{d}} \quad=-\sum_{j=1}^{14} \sum_{k=2}^{N} \frac{1}{2} \Delta \lambda_{k}\left\{\left[2 \bar{v}_{k-1}^{z} I_{k-1}\left(\dot{c}_{k-1} \cdot n_{j}+\left(\dot{c}_{x x}+\dot{c}_{y y-1}\right)_{k-1} \boldsymbol{n}_{j}\right)\right]+\right.$

$$
\left.+\left[2 \bar{v}_{k} z_{I_{k}}\left(\dot{c}_{k} \cdot n_{j}+\left(\dot{c}_{x x}+\dot{c}_{y y}\right)_{k} n_{j}\right)\right]\right\}
$$

$\left(\dot{c}_{k}\right)_{p q}=\left(\dot{i}_{1}\right)_{p q}+\left[\frac{\sum_{l=2}^{k} \Delta \lambda_{l}}{\sum_{m=2}^{N} i_{\Delta \lambda} m}\right]\left(\dot{c}_{N_{j}}-\dot{\boldsymbol{c}}_{1}\right)_{p q}$

$$
\bar{v}_{k} z \quad=\frac{\bar{B}^{z}}{2 i_{h}^{1-1 / n}}
$$

$$
\dot{c}_{k} \quad=\sum_{p=1}^{3} \sum_{q=1}^{3}\left[\frac{1}{2}\left(\dot{c}_{k}\right) p\left(\dot{c}_{k}\right) p q\right]^{1 / 2}
$$

$\operatorname{VAR}\left(F_{x}{ }^{\mathrm{f}}\right)=\left\{\sum_{j=1}^{14} \sum_{k=2}^{N}\left[\frac{1}{2} \Delta \lambda_{k} \sigma_{11}\left(n_{j}\right)_{x}\right]^{2}\left[\left[\rho_{i} g H_{k-1}+\frac{\alpha}{\beta}\left(g-e^{B H I_{k-1}}\right)\right]^{2}+\right.\right.$

$$
\left.\left.+\left[\rho_{i} g H_{k}+\frac{\alpha}{\beta}\left[g-e^{\beta H_{k}}\right]\right]^{2}\right]\right\}^{\frac{1}{2}}
$$

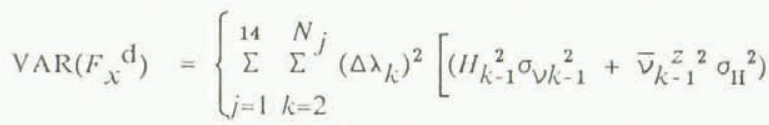$$
\left[\left(2 \dot{c}_{x x}+\dot{c}_{y y}\right)_{k-1}\left(n_{j}\right)_{x}+\left(\dot{c}_{x y}\right)_{k-1}\left(n_{j}\right)_{y}\right]^{2}+\left(I_{k}{ }^{2} \sigma_{\nu k}{ }^{2}+\bar{v}_{k}{ }^{22} \sigma_{\mathrm{HI}}{ }^{2}\right)
$$$$
\left[\left(2 \dot{c}_{x x}+\dot{e}_{y y}\right)_{k}\left(n_{j}\right)_{x}+\left(\dot{e}_{x y}\right)_{k}\left(n_{j}\right)_{y}\right]^{2}+\left(\bar{v}_{k-1}^{z}{ }^{2} H_{k-1}{ }^{2}+\bar{v}_{k}{ }^{22} H_{k}{ }^{2}\right)
$$$$
\left.\left.\left(5\left(n_{j}\right)_{x}{ }^{2}+\left(n_{j}\right)_{y}{ }^{2}\right) \sigma_{c}{ }^{2}\right]\right\}^{1 / 2}
$$

$\sigma_{\nu_{k}} \quad=\left\{\left[\frac{1}{2 \dot{c}_{k}^{1-1 / n}}\right] \sigma_{\mathrm{B}}{ }^{2}+\left(\frac{\overline{B^{2}}(1 / n-1)}{2 \dot{e}_{k}^{2-1 / n}}\right)^{2} \sigma_{\mathrm{eps}}{ }^{2}\right\}^{\frac{1}{2}}$

$\sigma_{\text {eps }} \quad=\left\{\left(\frac{1}{2} \frac{1}{\dot{c}}\right]^{2}\left[\left(2 \dot{e}_{x x}+\dot{e}_{y y}\right)_{k}{ }^{2}+\left(2 \dot{e}_{y y}+\dot{e}_{x x}\right)_{k}{ }^{2}+\left(2 \dot{e}_{x y}\right)^{2}{ }_{k}\right] \sigma_{e}{ }^{2}\right\}^{\frac{1}{2}}$ 
Advective mass flux through $\Gamma$

Interpolated velocity

Uncertainty of $Q$

Energy dissipation rate by work done against dynamic drag

Uncertainty of $W^{*}$

$$
\begin{aligned}
Q \quad= & -\sum_{j=1}^{14} \sum_{k=2}^{N} \frac{\Delta \lambda_{k}}{2}\left\{\left[\rho_{\mathrm{i}} H_{k-1}+\frac{\alpha}{\beta}\left[1-e^{\beta H_{k-1}}\right]\right] u_{k-1} \cdot \boldsymbol{n}_{j}+\right. \\
& \left.+\left[\rho_{\mathrm{i}} H_{k}+\frac{\alpha}{\beta}\left[1-e^{\beta H_{k}}\right]\right] u_{k} \cdot n_{j}\right\} \\
u_{k .} \quad=u_{1}+ & \sum_{\sum_{m=2}^{N} \Delta \lambda_{m}}^{k} \Delta \lambda_{l}
\end{aligned}
$$

W

$=\sum_{j=1}^{14} \sum_{k=2}^{N} \frac{\Delta \lambda_{k}}{2}\left\{-2 \bar{v}_{k-1}^{z} H_{k-1} u_{k-1} \cdot\left(\dot{e}_{k-1} \cdot n_{j}+\left(\dot{e}_{x x}+\dot{e}_{y y}\right)_{k-1} n_{j}\right)-\right.$

$-2 \bar{v}_{k}^{2} H_{k} u_{k} \cdot\left(\dot{e}_{k} \cdot n_{j}+\left(\dot{e}_{x x}+\dot{e}_{y y}\right)_{k} n_{j}\right)+\left(u_{k-1} \cdot n_{j}\right)$

$\left[\frac{1}{2} \rho_{\mathrm{i}} g H_{k-1}^{2}+\frac{\alpha}{\beta} g H_{k-1}+\frac{\alpha}{\beta^{2}} g\left[1-e^{\beta H_{k-1}}\right]-\right.$

$\left.-\frac{1}{2} \frac{g}{\rho_{\mathrm{W}}}\left[\rho_{\mathrm{i}} H_{k-1}+\frac{\alpha}{\beta}\left[1-e^{\beta H_{k-1}}\right]\right]^{2}\right]+\left(u_{k} \cdot n_{j}\right)$

$\left[\frac{1}{2} \rho_{\mathrm{i}} g H_{k}^{2}+\frac{\alpha}{\beta} g H_{k}+\frac{\alpha}{\beta^{2}} g\left[1-e^{\beta H_{k}}\right]-\right.$

$\left.\left.-\frac{1}{2} \frac{g}{\rho_{\mathrm{w}}}\left[\rho_{\mathrm{i}} H_{k}+\frac{\alpha}{\beta}\left[1-e^{\beta H_{k}}\right]\right]^{2}\right]\right\}$

$\operatorname{VAR}(W)=\left\{\begin{array}{cc}14 & N_{j} \\ \sum=1 & k=2\end{array}\left(\frac{\Delta \lambda_{k}}{2}\right)^{2}\left[\sigma_{\mathrm{H}}^{2}\left(\frac{\partial W}{\partial H_{k}}\right)^{2}+\left(\frac{\partial W}{\partial H_{k-1}}\right)^{2}\right]+\right.$

$+\sigma_{\mathrm{u}}^{2}\left[\left(\frac{\partial W}{\partial u_{x k}}\right)^{2}+\left[\frac{\partial W}{\partial u_{y k}}\right]^{2}+\left[\frac{\partial W}{\partial u_{x-1}}\right]^{2}+\left[\frac{\partial W}{\partial u_{y_{k-1}}}\right]^{2}\right]+$

$+\sigma_{\mathrm{e}}^{2}\left[\left(\frac{\partial W}{\partial \dot{e}_{x x k}}\right)^{2}+\left[\frac{\partial W}{\partial \dot{e}_{y y k}}\right]^{2}+\left[\frac{\partial W}{\partial \dot{e}_{x y k}}\right]^{2}+\left[\frac{\partial W}{\partial \dot{e}_{x x_{k-1}}}\right]^{2}+\right.$

$\left.\left.\left.+\left[\frac{\partial W}{\partial \dot{e}_{y y_{k-1}}}\right]^{2}+\left[\frac{\partial W}{\partial \dot{e}_{x y_{k-1}}}\right]^{2}\right]+\sigma_{\nu}^{2}\left[\frac{\partial W}{\partial \bar{v}_{k}^{z}}\right]^{2}+\sigma_{\nu}{ }^{2}\left[\frac{\partial W}{\partial \bar{\nu}_{k-1} z}\right]^{2}\right]\right\}^{\frac{1}{2}}$

*We present the uncertainty of $W$ in abstract form for brevity. 